\title{
المشروعات الزراعية الصغيرة ودورها في تقليل البطالة وأثرها على التنمية المستدامة
}

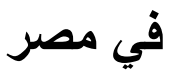

دعاء إبراهيم عبد الحميا هاشم

باحث

\section{شيرين محمد عفت الفار}

باحث أول

معهد بحوث الاقتصاد الزراعي-مركز البحوث الزراعية

الملخص: تعثبر المشروعات الصغيرة من أهم مقومات عملية التتمية الإقتصادية والإجتماعية فى مصر لما لها لهاعيه

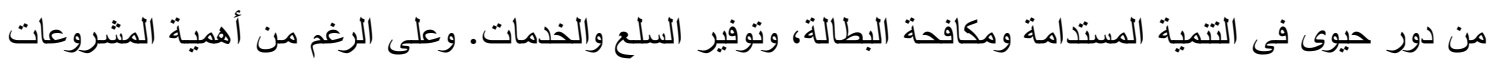

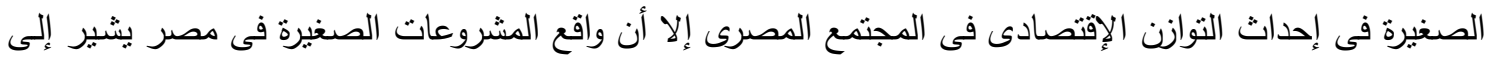

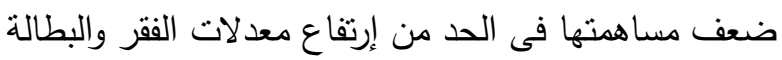

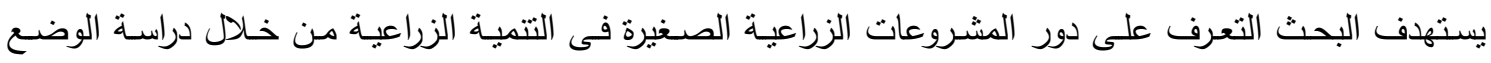

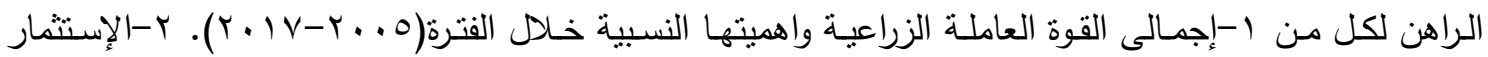
القومي والاستشمارات الزراعيـة العامـة والخاصـة والقروض الممنوحـة للمشروعات الصغيرة بمحافظـة البحيرة خـلال

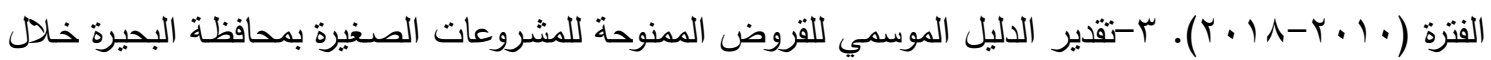

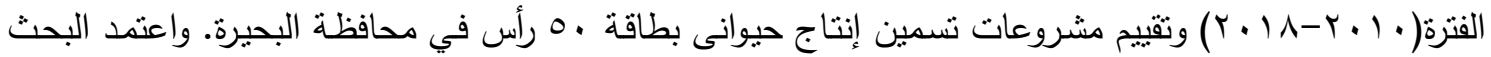
على كل من اسلوب التحليل الوصفي، والكمي.

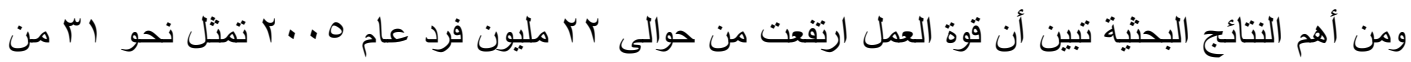

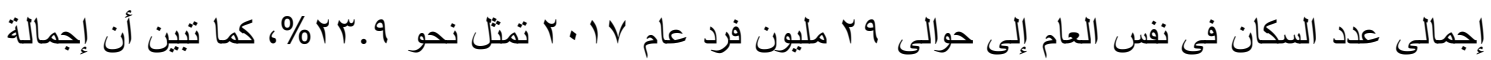

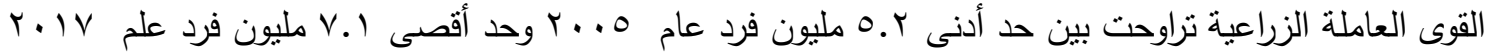
بمتوسط بلـغ حوالى ؟ بـ مليون فرد، وتبين أن إجمـالى قيمـة القروض المقدمـة للمشـروعات الزراعيـة الصـغيرة

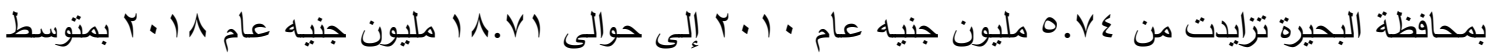

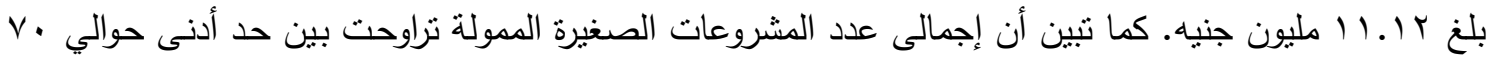

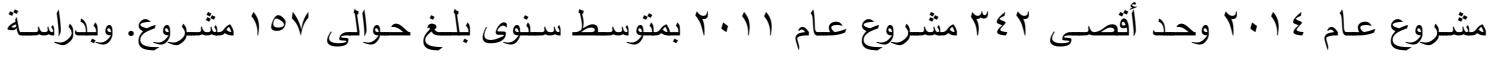

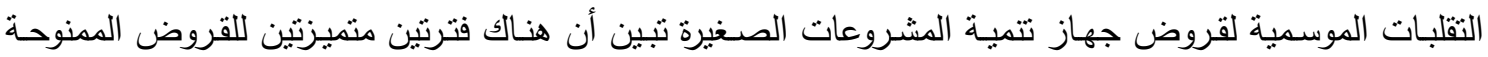
للمرأة الريفية هما شهور فبراير ، مارس، مايو ، يوليو، ديسمبر وتتسم بزيادة القروض الممنوحة ، بينما تنخفض فى

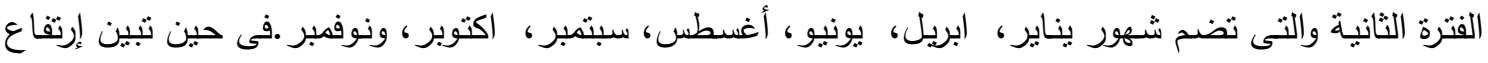

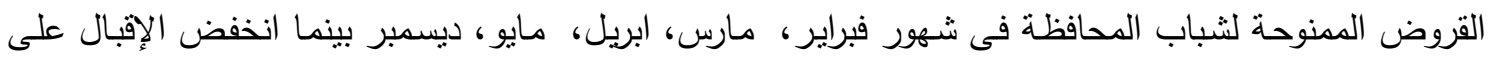

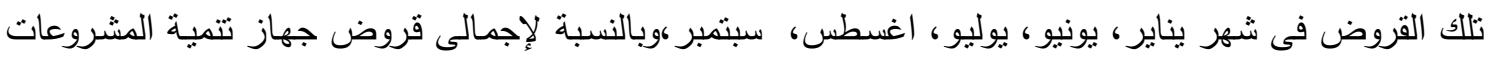

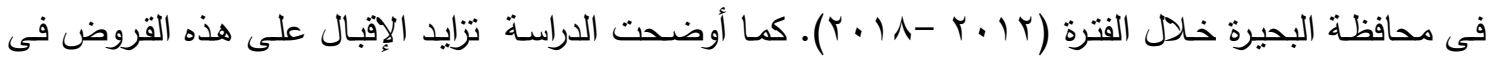
شهور فبراير، مارس، ابريل، مايو ، يوليو ،ديسمبر ، فى حين إنخفض فى شهور يناير ، يونيو ، اغسطس، سبتمبر ،

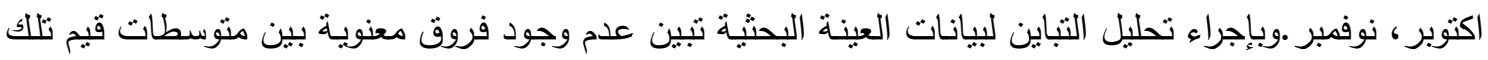
القروض المقدمة لكل من المرأة الريفية وشباب المحافظة. 
تعتبر المشروعات الصغيرة من أهم مقومات عملية التتمية الاقتصادية والإجتماعية في مصر لما لها من دور

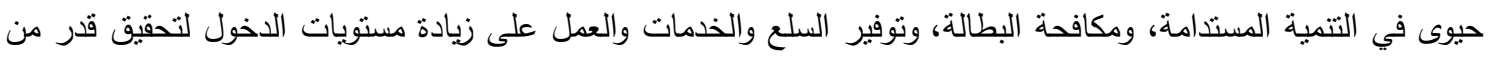

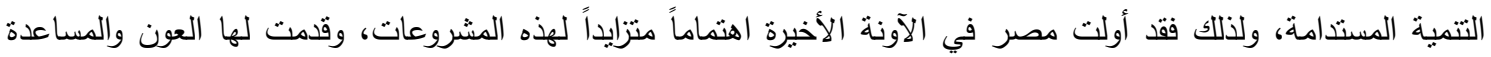

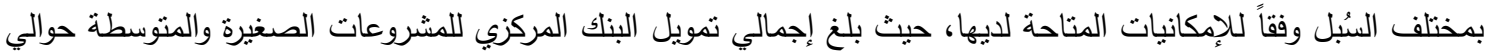

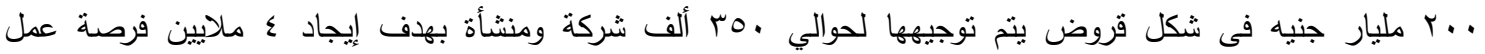

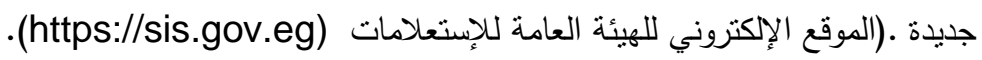

ويتجلى دور الدولـة في الإهتمـام بالمشـروعات الصـغيرة بنقل تبعيتها إلـى جهـاز نتميـة المشـروعات الصـغيرة

والمتوسطة لرئاسة مجلس الوزراء، و يتألف من عضوية مجموعة من الوزراء ونائب محافظ البنك المركزى والرئيس التتفيذى دئى للجهاز وذلك من أجل تقوية أدوأه ودعم دوره الفعال في تمويل مشروعات الشباب لتحقيق طموحاتهم، ويهيى الجهاء الجهاز البيئة

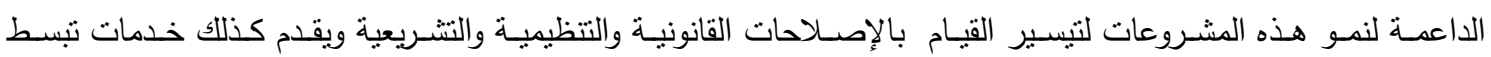

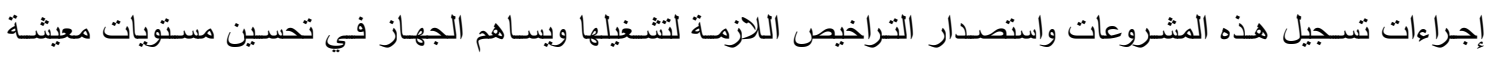
المواطنين من خلال تتفيذ مشروعات البنية الأساسية والمجتمعية ، و يوفر حزماً متكاملة من برامج التمويل وخدمات تتمية

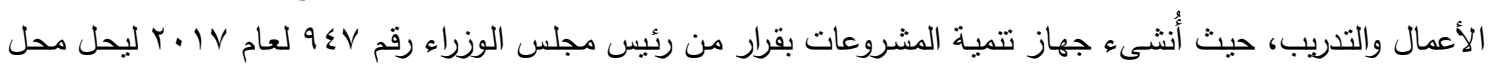

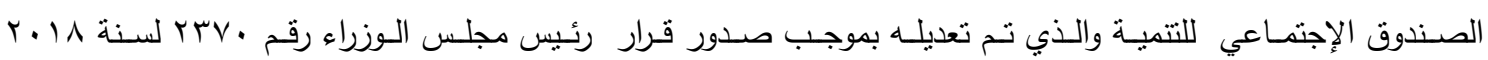

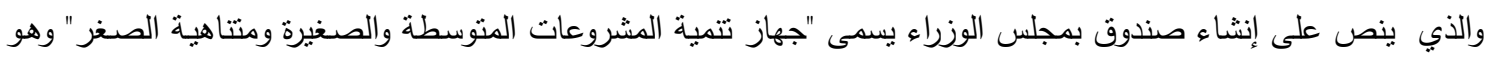

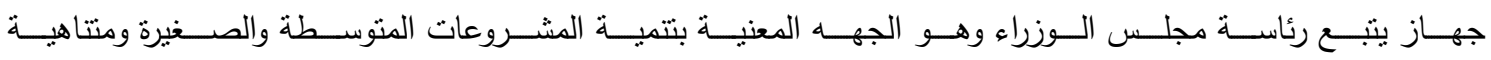
الصغر وريادة الأعمال سواء بصفة مباشرة أو من خلال تتسيق جهود كافة الجهات والجمعيات الأهلية والمبادرات العاملة في

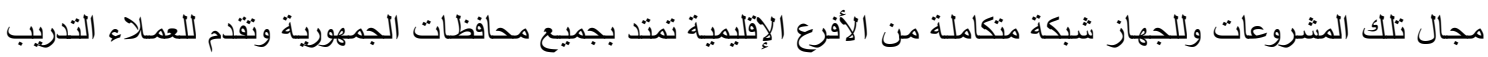
والمساندة الفنية والإدارية والتمويل وخدمات الثباك الواحد. (www.potrsaid.gov.eg).

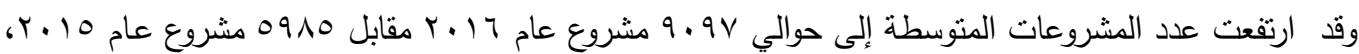

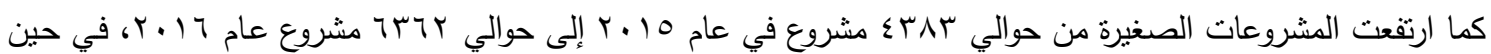

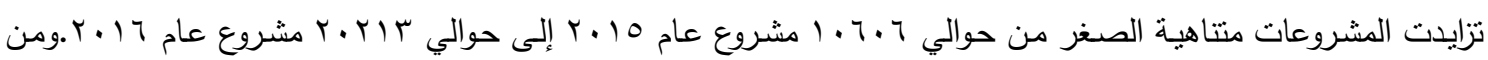

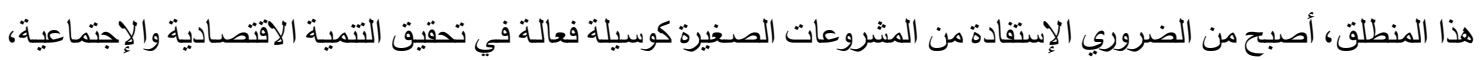
وتقليل معدل البطالة في مصر .

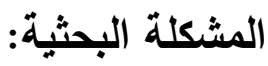

تعتبر المشـروعات الزراعيـة الصغيرة أحد أهم السُبل التي يمكن من خلالها امتصـاص جزء كبير من

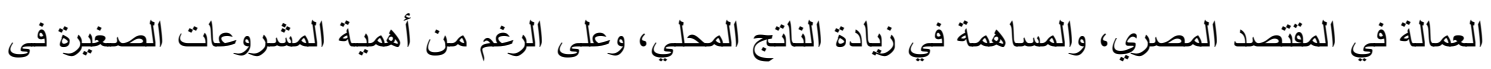

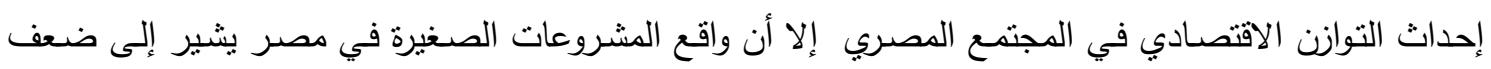

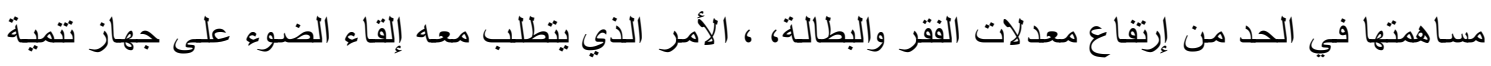
المشروعات ودوره في توفير التمويل اللازم للمشروعات الصغيرة. 


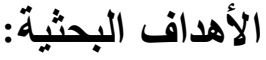

يستهدف البحث بصفة أساسية التعرف على دور المشروعات الزراعية الصغيرة فى التنمية الاقتصادية الزراعية من خلال دراسة الأهداف الفرعية التالية:

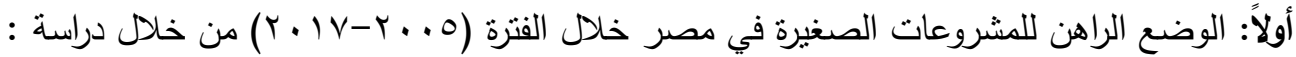
1- نطور القوى العاملة وإجمالي الناتج المحلي والناتج المحلي الزراعي في مصر خلال الفترة

$$
\cdot(r+1 V-r+.0)
$$

r- تطور الإستثمار القومي والإستثمارات الزراعية، وقيمة المدخرات الزراعية والقروض الزراعية خلا

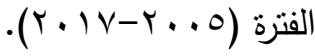

ثانياً : القروض الممنوحة من جهاز تتمية المشروعات للمشروعات الصغيرة بمحافظة البحيرة خلال الفترة

$$
\cdot(r \cdot 1 \Lambda-r \cdot 1 \cdot)
$$

ثالثاً : تقدير الدليل الموسمي للقروض الممنوحة من جهاز تتمية المشروعات للمشروعات الصغيرة بمحافظة

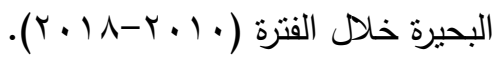

رابعا: تحليل التباين لمفردات العينة البحثية في محافظة البحيرة .

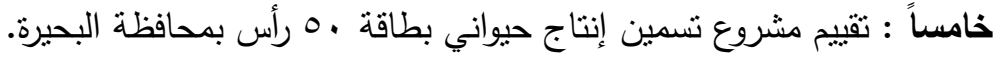

\section{الأسلوب البحثي و مصادر البيانات:}

اعتمد البحث في تحقيق أهدافه على كلٍ من أسلوب التحليل الوصفي المتمنل في المتوسطات والنسب المئوية والعرض الجدولي بالإضافة إلى أسلوب التحليل الكمي حيث نم تقدير معدلات النمو السنوي للمتغيرات الإقتصادية موضع الدراسة بإستخدام دالة النمو. قد اعتمد البحث على البيانات الثانوية المنشورة وغير المنشورة فى لئ العديد من الهيئات مثل وزارة التخطيط، قطاع الثئون الإقتصادية بوزارة الزراعة، والصندوق الإجتماعي للتتمية،

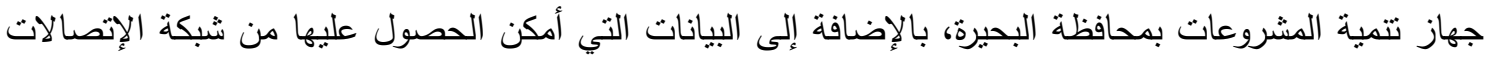
والمعلومات الدولية منل موقع وزارة التتمية الإقتصادية، وموقع مركز المعلومات ودعم إتخاذ القرار بمجلس الوزراء المصرى، كما تم الإعتماد على البيانات الأولية التي تم الحصول عليها من خلال إستمارة الإستبيان لعينة بحثية تم

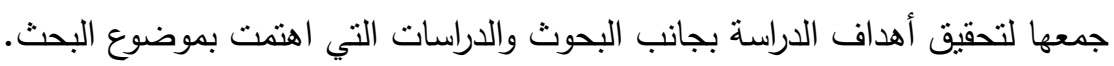

\section{مفاهيم بحثية:}

المشروعات الصغيرة وأنواعها: لا يوجد تعريف متفق عليه بحدد ماهية المشروعات الصغيرة، ويعزى ذلك إلى أن اعتماد معيار معين للتعريف سواء من حيث عدد العمال أو رأس المال المستثر أو المستوى التقني، سينجم عنه نتائج متباينة تبعا لتباين الدول وطبيعة هياكلها الاقتصادية والاجتماعية، ولكن هنالك عدد من التعريفات التي تتطلق بشكل

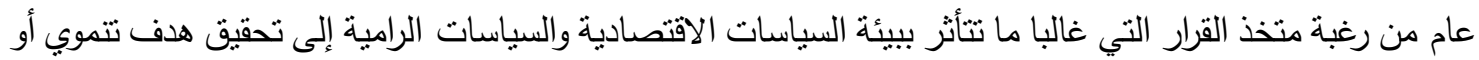

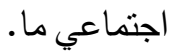
تعرف منظمة الأمم المتحدة للتنمية الصناعية" يونيدو "المشروعات الصغيرة بأنها: "تلك المشروعات التي يديرها

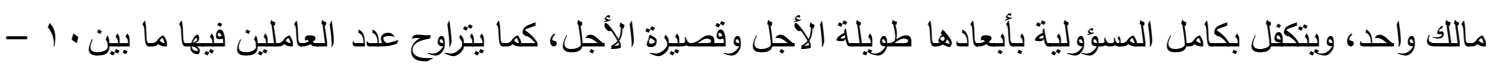

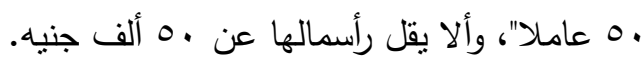


وهناك معايير عديدة يمكن الإسنتاد إليها لتحديد مفهوم المشروعات الصغيرة، وتتباين تلك المعايير بين دولة وأخرى وذللك بتباين إمكاناتها وقدراتها وظروفها الاقتصادية ومراحل النمو التي بلغتها، فالمشروعات التي تعتبر صغيرة أو منوسطة الحجم في دولة صناعية قد تعتبر مشروعات كبيرة الحجم في دولة نامية.

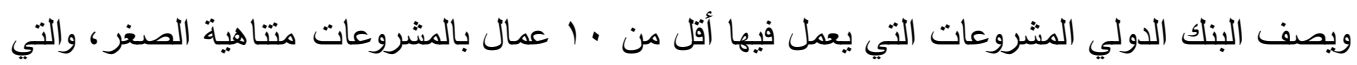

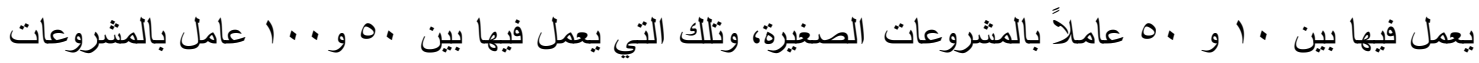
المتوسطة.

\section{النتائج البحثية ومناقتشتها:}

أولاً: الوضــع الراهـــن لبعض المؤثـــرات الإقتصاديــة للمشروعـات الصغيـرة في مصــــر خلال الفتـــرة $\cdot(r+1 V-r+0)$

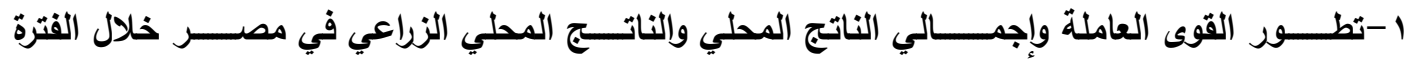
$\cdot(r+1 V-r+0)$

تبين من استعراض تطور القوى العاملة وإجمالي الناتج المحلي والناتج المحلي الزراعي في مصر خلال الفترة

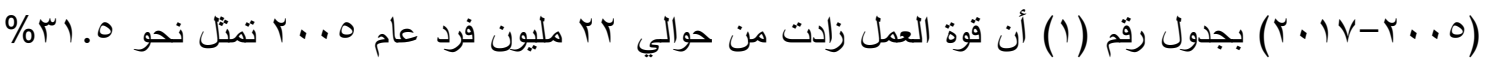

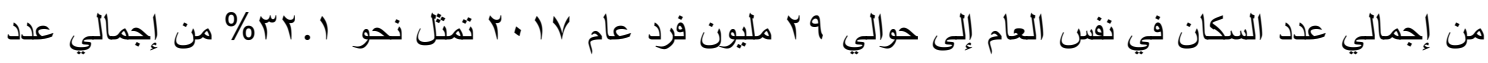

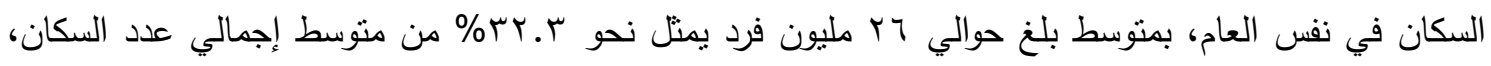

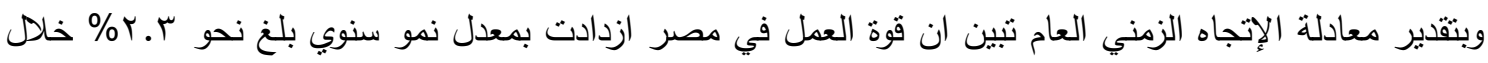

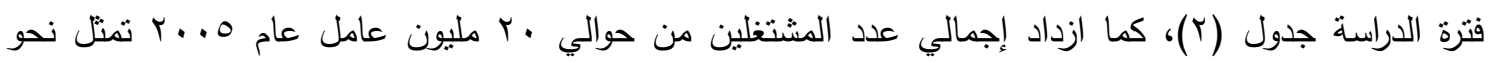

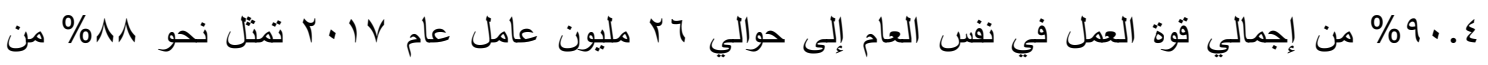

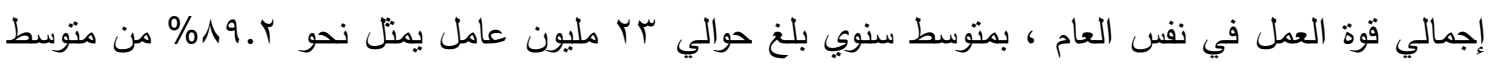

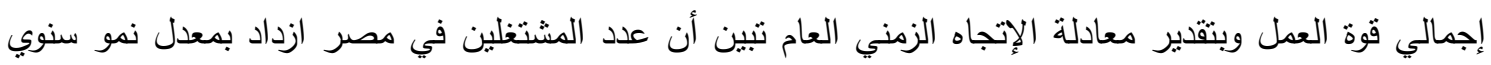

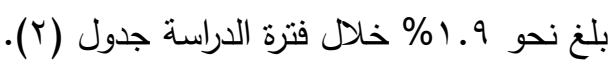

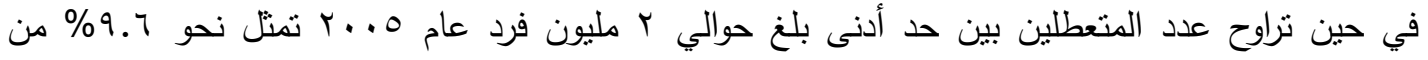

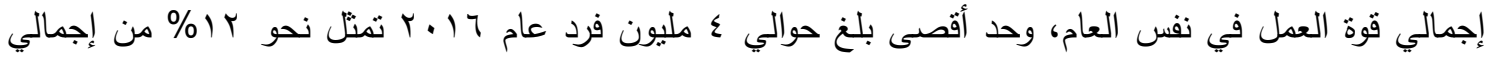

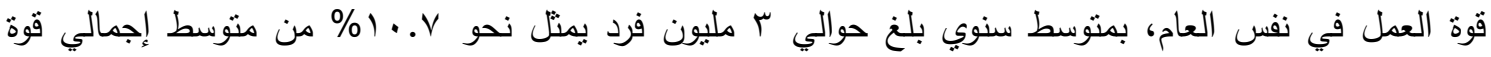

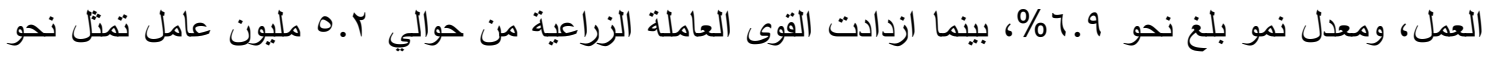

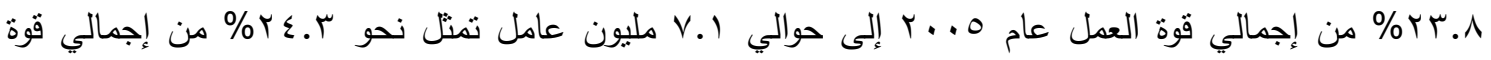

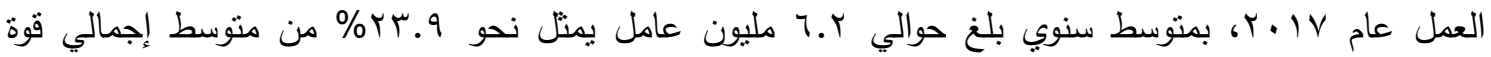
العمل. وبتقدير معادلة الإتجاه الزمني العام تبين أن عدد المتعطلين في مصر ازداد بمعدل نمو سنوي بلغ نحو ؟. \% خلال فترة الدراسة جدول (r). 


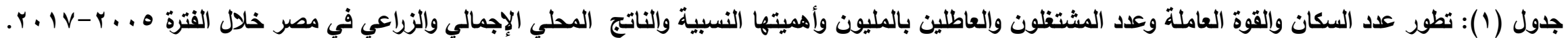

\begin{tabular}{|c|c|c|c|c|c|c|c|c|c|c|c|c|}
\hline 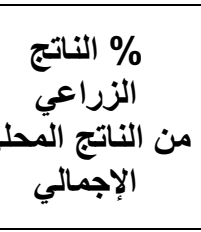 & (لزاراعي & الناتج المحلي & من القوى العماملية & \% من قوة العطلون & من المشتفلين & \% من عدة العمل & الزالعمالي & (مليون فرد) & إلجمالي عدلين & قوة العمل & عدد السكان & السنة \\
\hline 14.9 & 75.3 & 506.5 & 23.8 & 9.6 & 90.4 & 31.5 & 5.2 & 2 & 20 & 22 & 69 & 2005 \\
\hline 14.1 & 81.9 & 581.1 & 23.1 & 9.3 & 90.7 & 31.8 & 5.2 & 2 & 20 & 22 & 71 & 2006 \\
\hline 14.1 & 99.9 & 710.4 & 22.2 & 8.9 & 91.1 & 33.0 & 5.3 & 2 & 22 & 24 & 72 & 2007 \\
\hline 13.2 & 113 & 855.3 & 21.9 & 8.7 & 91.3 & 33.5 & 5.4 & 2 & 23 & 25 & 74 & 2008 \\
\hline 13.6 & 135.4 & 994.1 & 22.1 & 9.4 & 90.6 & 33.7 & 5.6 & 2 & 23 & 25 & 75 & 2009 \\
\hline 14.0 & 160.9 & 1150.6 & 26.4 & 9.2 & 90.8 & 34.1 & 6.9 & 2 & 24 & 26 & 77 & 2010 \\
\hline 14.5 & 190.1 & 1309.9 & 25.6 & 12.0 & 88.0 & 33.7 & 6.8 & 3 & 23 & 27 & 79 & 2011 \\
\hline 12.8 & 188.8 & 1475.3 & 23.7 & 12.7 & 87.3 & 33.6 & 6.4 & 3 & 24 & 27 & 80 & 2012 \\
\hline 12.5 & 209.8 & 1677.4 & 25.0 & 13.2 & 86.8 & 33.5 & 6.9 & 4 & 24 & 28 & 83 & 2013 \\
\hline 12.6 & 241.5 & 1910.6 & 24.3 & 13.0 & 87.0 & 33.0 & 6.8 & 4 & 24 & 28 & 85 & 2014 \\
\hline 11.2 & 275 & 2458.5 & 21.8 & 12.8 & 87.2 & 32.7 & 6.2 & 4 & 25 & 28 & 87 & 2015 \\
\hline 11.9 & 318.8 & 2673.3 & 22.4 & 12.5 & 87.5 & 32.1 & 6.4 & 4 & 25 & 29 & 89 & 2016 \\
\hline 11.7 & 398.5 & 3409.5 & 24.3 & 12.0 & 88.0 & 32.1 & 7.1 & 3 & 26 & 29 & 91 & 2017 \\
\hline 13.1 & 191.5 & 1516.3 & 23.6 & 10.9 & 89 & 32.9 & 6.2 & 3 & 23 & 26 & 79 & المتوسط \\
\hline 15.1 & 179.7 & Irqr.o & rT.O & $1 \cdot .9$ & 19. & r. . $q$ & 7.1 & T.V & rT. & r૫. & va.1 & المندسي \\
\hline
\end{tabular}

المصدر : - وزارة التمية الاقتصادية، خطة التتمية الاقتصادية والإجتماعية، أعداد منفرقة.

- الجهاز المركزي للتعبئة العامة والإحصاء، أعداد متفرقة. 
بينما تراوحت قوة العمل الزراعية بين حد أدنى بلغ حوالي ب.0 مليون فرد عام O. . ب تمثل نحو

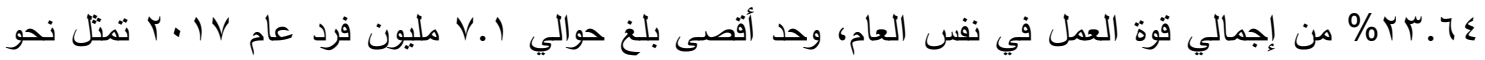

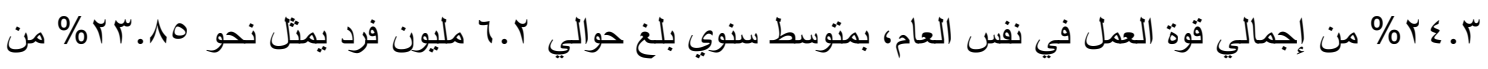

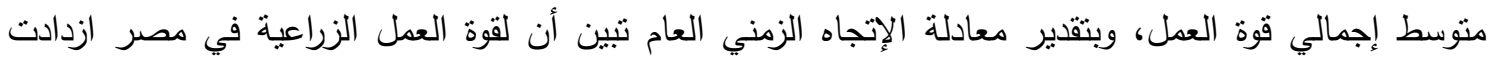

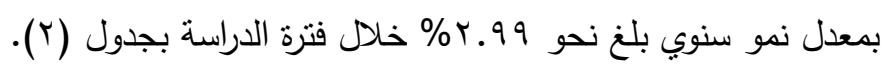

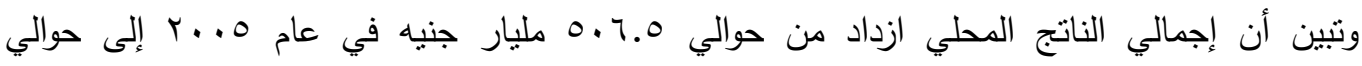

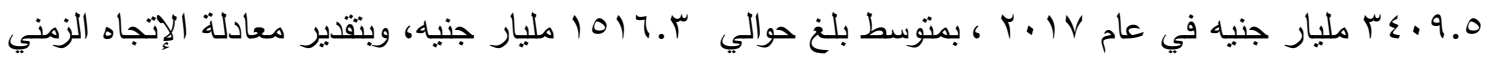

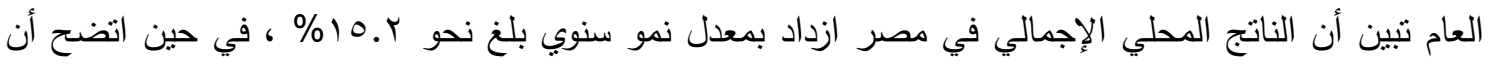

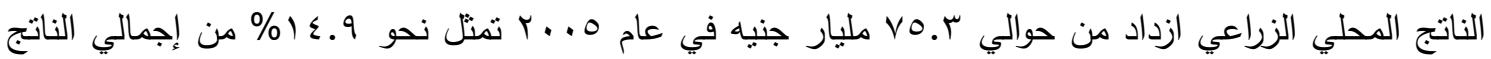

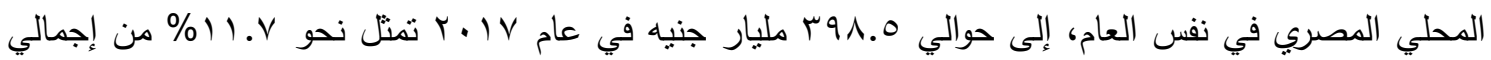

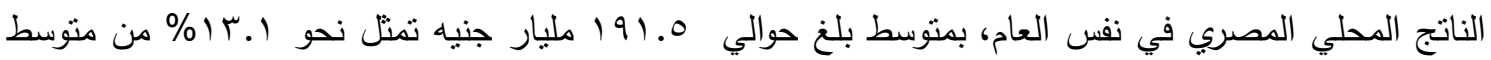
إجمالي الناتج المحلي المصري خلال فترة الدراسة، وبتقدير معادلة الإتجاه الزمني العام تبين أن الناتج المحلي

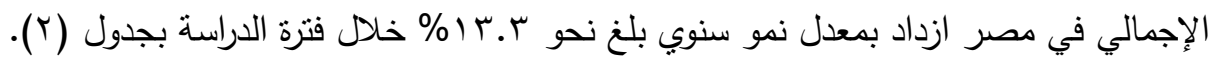

جدول رقم (ץ): نتائج معادلات الإتجاه الزمني العام للمتغيرات قوة العمل، أعداد المشتظلين، أعداد المتعطلين، وإجمالي

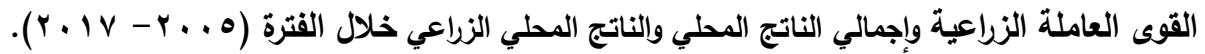

\begin{tabular}{|c|c|c|c|c|}
\hline $\mathbf{F}$ & $\mathbf{R}^{2}$ & المعادلة & المثتثير المستثمل & ريم المعادلة \\
\hline$(125.67)^{* *}$ & 0.912 & $\begin{aligned} \mathrm{LnY} Y_{\mathrm{t}}= & 3.09+0.0234 \mathrm{~T}_{\mathrm{i}} \\
& (186.8)^{* *}(11.21)^{* *}\end{aligned}$ & كوه العمل & (') \\
\hline$(59.87)^{* *}$ & 0.83 & $\begin{aligned} & \operatorname{LnY} Y_{t}=3.02+0.0189 T_{i} \\
&(156.66)^{* t} \\
&(7.37)^{* t}\end{aligned}$ & أعداد المشُثخلْين & $\left({ }^{(}\right)$ \\
\hline$(29.10)^{* * *}$ & 0.726 & $\begin{array}{l}\mathrm{LnY} \\
\quad=0.517+0.069 \mathrm{~T}_{\mathrm{i}} \\
(5.39)^{*}\end{array}$ & أعداد المثعطلين & $\left({ }^{\top}\right)$ \\
\hline$(158.57)^{* *}$ & 0.929 & $\begin{aligned} \operatorname{LnY} & =1.60+0.0299 \mathrm{~T}_{i} \\
& (84.95)^{* *}(12.59)^{*}\end{aligned}$ & إجمالي القوى العاملة الزراعية & $(\S)$ \\
\hline$(2391)^{* *}$ & 0.995 & $\begin{aligned} \operatorname{LnY} Y_{t} & =6.09+0.152 \mathrm{~T}_{\mathrm{i}} \\
& (246.4)^{+*}(48.89)^{* *}\end{aligned}$ & لملي & (०) \\
\hline$(938)^{* *}$ & 0.987 & $\begin{array}{l}\operatorname{LnY}_{t}=4.20+0.133 \mathrm{~T}_{\mathrm{i}} \\
\quad(122.23)^{* *}\end{array}$ & الثاتج المحلي الزراعي & (7) \\
\hline
\end{tabular}

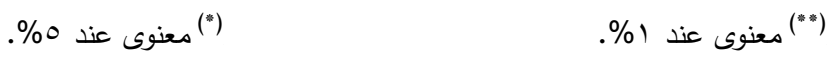

المصدر :جمعت وحسبت من بيانات جدول رقم ( ) 


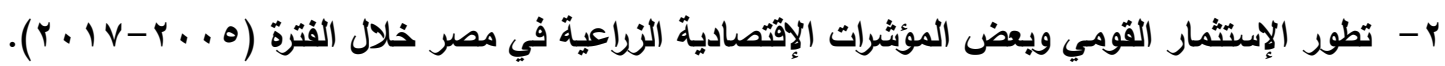

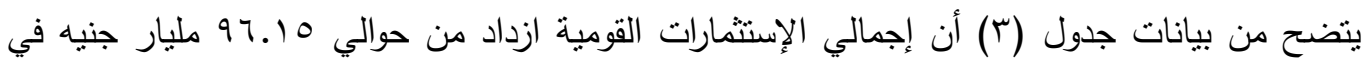

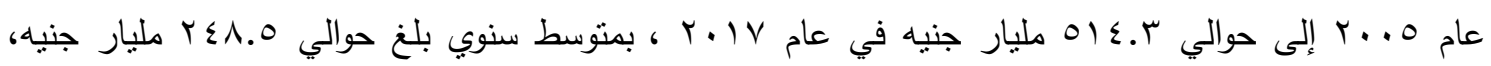

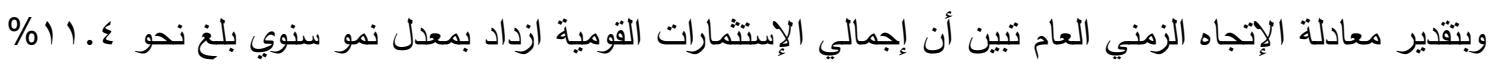

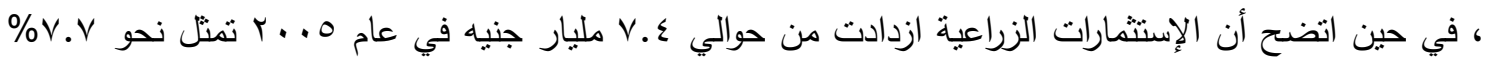

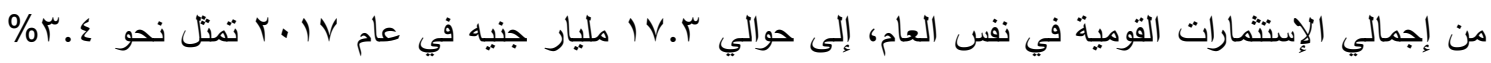

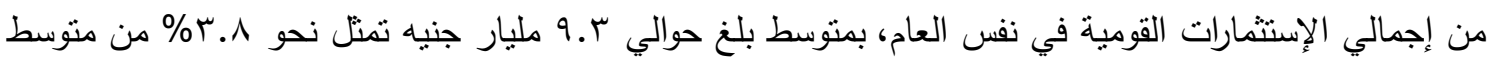

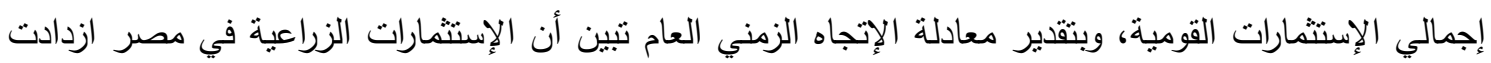

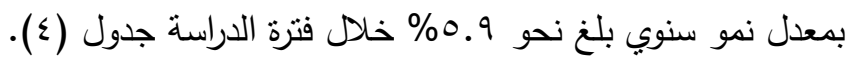

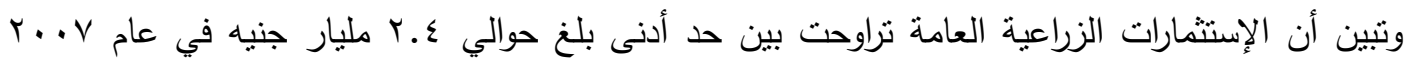

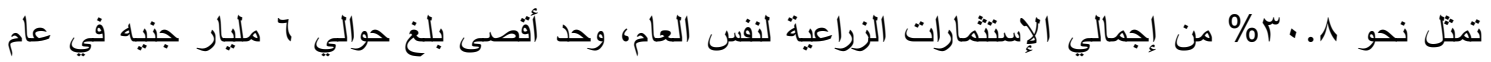

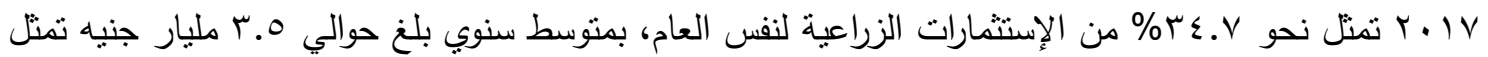

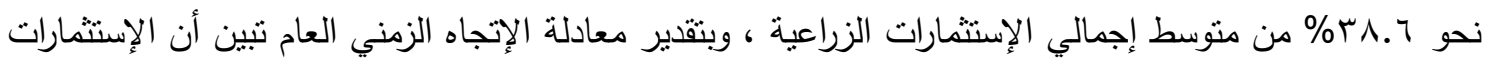

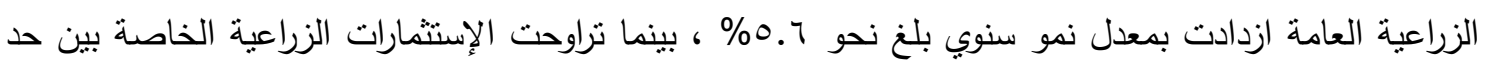

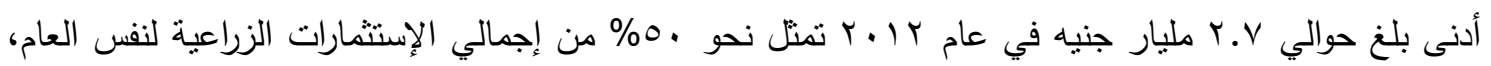

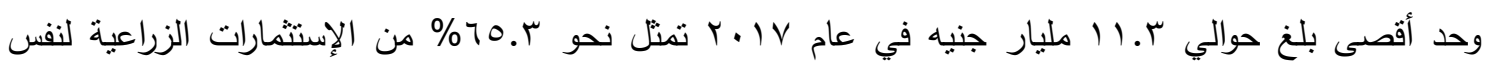

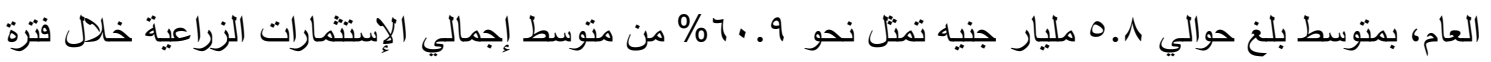

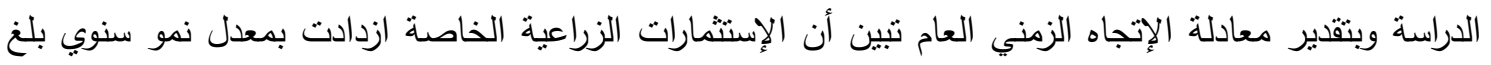

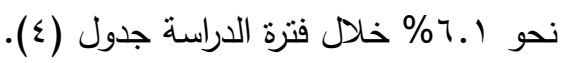

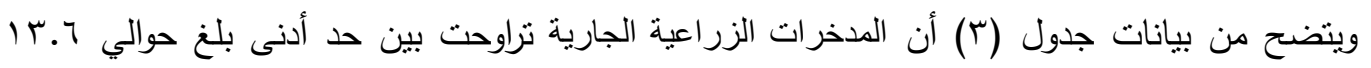

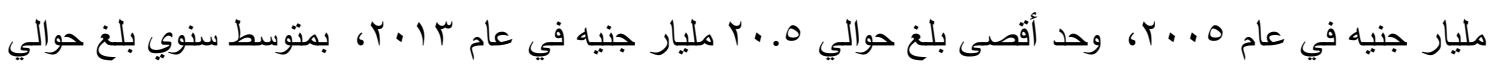

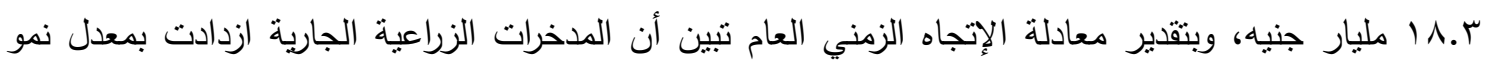

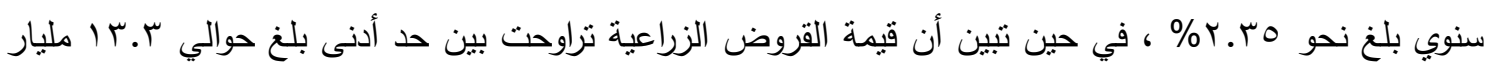

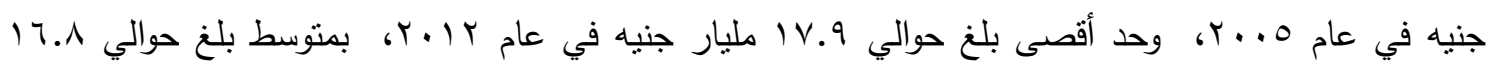

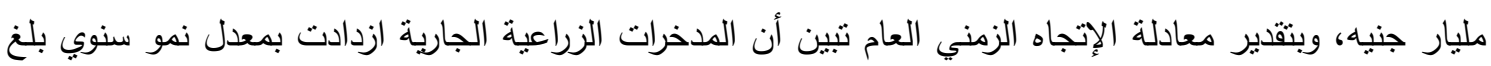

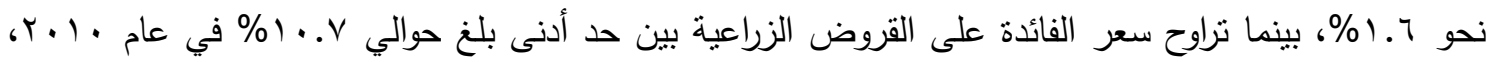

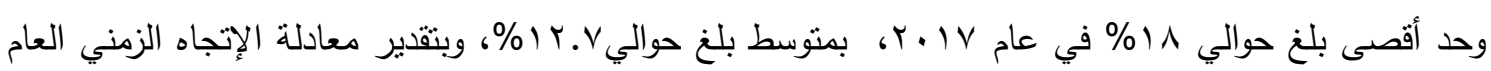

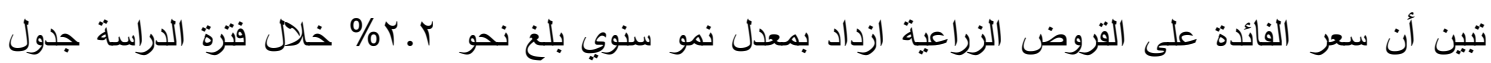




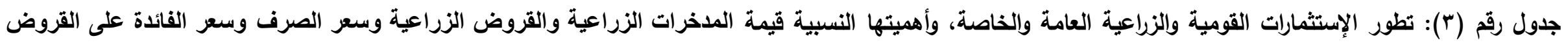

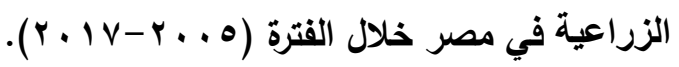

\begin{tabular}{|c|c|c|c|c|c|c|c|c|c|c|c|}
\hline سعرض الفائدة على الزراعية & سرف & قيمة القروضة الزراعية & المدخرات الزراعية & الإستثمارات & الإستثمارات & الإستثمارات & الإستثمارات & الإستثمارات & الإستثماراتي & الإستثمارات & السنوات \\
\hline$\%$ & جنيه/دولار & مليار جنيه & مليار جنيه & الزراعية & الزراعية & من القومية & مليار جنيه & مليار جنيه & مليار جنيه & مليار جنيه & \\
\hline 12.7 & 5.7 & 13.3 & 13.6 & 58.1 & 43.2 & 7.7 & 4.3 & 3.2 & 7.5 & 96.1 & 2005 \\
\hline 12.6 & 5.7 & 15.4 & 15.9 & 65.0 & 35.0 & 6.9 & 5.2 & 2.8 & 8 & 115.7 & 2006 \\
\hline 12.2 & 5.5 & 15.8 & 16.7 & 69.2 & 30.8 & 5.0 & 5.4 & 2.4 & 7.8 & 155.3 & 2007 \\
\hline 12.6 & 5.5 & 16.4 & 17.4 & 64.2 & 35.8 & 4.1 & 5.2 & 2.9 & 8.1 & 199.5 & 2008 \\
\hline 11.0 & 5.8 & 17 & 18.2 & 59.4 & 39.1 & 3.5 & 4.1 & 2.7 & 6.8 & 197.2 & 2009 \\
\hline 10.7 & 6.0 & 17.6 & 18.9 & 57.4 & 42.6 & 2.9 & 3.9 & 2.9 & 6.8 & 231.8 & 2010 \\
\hline 11.8 & 6.3 & 17.8 & 19.4 & 52.9 & 48.5 & 3.0 & 3.6 & 3.3 & 6.9 & 229.1 & 2011 \\
\hline 12.2 & 6.9 & 17.9 & 20.3 & 50.0 & 50.0 & 2.2 & 2.7 & 2.7 & 5.4 & 246.0 & 2012 \\
\hline 11.9 & 7.1 & 17.2 & 20.5 & 62.7 & 37.3 & 3.4 & 5.2 & 3.1 & 8.3 & 241.6 & 2013 \\
\hline 11.8 & 8.8 & 17.6 & 18.8 & 57.1 & 42.9 & 2.7 & 4.4 & 3.3 & 7.7 & 280.6 & 2014 \\
\hline 13.8 & 8.9 & 17.4 & 19.3 & 65.4 & 34.6 & 4.0 & 8.7 & 4.6 & 13.3 & 330.9 & 2015 \\
\hline 16.3 & 8.9 & 17.5 & 19.5 & 67.9 & 32.1 & 4.2 & 11.2 & 5.3 & 16.5 & 392.0 & 2016 \\
\hline 18.0 & 18.0 & 17.5 & 19.4 & 65.3 & 34.7 & 3.4 & 11.3 & 6.0 & 17.3 & 514.3 & 2017 \\
\hline 12.8 & 7.6 & 16.8 & 18.3 & 60.9 & 38.6 & 3.8 & 5.8 & 3.5 & 9.3 & 248.5 & المتوسط \\
\hline 7.17 & 16.75 & 18.19 & 60.86 & 38.55 & 3.83 & 5.28 & 3.34 & 8.68 & 8.67 & 226.01 & الهنتوسي \\
\hline
\end{tabular}


جدول رقم (ء): نتائج معادلات الإتجاه الزمني العام لمتغيرات الإستثمار القومي والإستثمارات الزياعية،

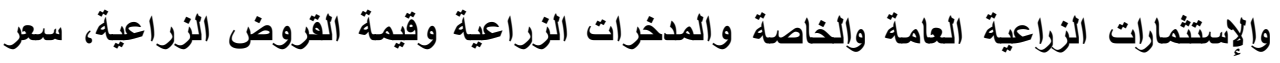

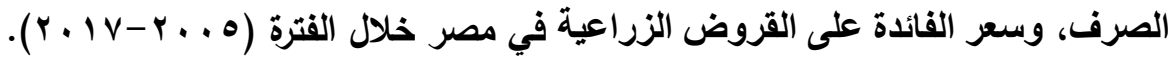

\begin{tabular}{|c|c|c|c|c|}
\hline $\mathbf{F}$ & $\mathbf{R}^{2}$ & المعادلة & المثتير المستطل & المعادئة \\
\hline$(137)^{*}$ & 0.919 & $\begin{aligned} \operatorname{LnX} & =4.63+0.114 \mathrm{~T}_{\mathrm{i}} \\
(60.03)^{*} & (11.71)^{*}\end{aligned}$ & الإستخمار القومى & (1) \\
\hline$(8.0)^{\circ}$ & 0.421 & $\begin{aligned} \operatorname{LnX}= & 1.74+0.059 \mathrm{~T}_{\mathrm{i}} \\
& (10.43)^{*}(2.83)^{-}\end{aligned}$ & الإستمارات الزراعبة & $(r)$ \\
\hline$(16.83)^{-*}$ & 0.604 & $\begin{aligned} \mathrm{LnX}= & 0.816+0.0558 \mathrm{~T}_{\mathrm{i}} \\
& (7.56)^{*}{ }^{*}(4.10)^{-*}\end{aligned}$ & الإستمارات الزراعبة العامة & (r) \\
\hline$(4.88)^{\circ}$ & 0.307 & $\begin{aligned} \operatorname{LnY}= & 1.23+0.0612 \mathrm{~T}_{\mathrm{i}} \\
& (5.61)^{*}(2.21)^{\circ}\end{aligned}$ & الإنتمارات الزراعبة الخاصـة & $(\varepsilon)$ \\
\hline$(19.29)^{*-}$ & 0.637 & $\begin{aligned} \operatorname{LnY}_{\mathrm{t}} & =2.74+0.0235 \mathrm{~T}_{\mathrm{i}} \\
\quad(64.51)^{-*} & (4.39)^{*}\end{aligned}$ & الدخرات الزراعبة الجارية & (०) \\
\hline$(14.21)^{*}$ & 0.564 & $\begin{array}{l}\operatorname{LnY_{t}}=2.71+0.0161 \mathrm{~T}_{\mathrm{i}} \\
\quad(80.0)^{-*} \\
(3.77)^{-*}\end{array}$ & قَلِمة القروض الزراعِية & (ך) \\
\hline$(25.95)^{-*}$ & 0.675 & $\begin{array}{r}\operatorname{LnY}=1.47+0.0715 \mathrm{~T}_{\mathrm{i}} \\
(13.19)^{*}(5.09)^{*}\end{array}$ & سعر الصرف & (v) \\
\hline$(5.50)^{*}$ & 0.333 & $\begin{array}{r}\operatorname{LnX}=2.39+0.0218 \mathrm{~T}_{\mathrm{i}} \\
(32.48)^{*}(2.35)^{\circ}\end{array}$ & سعر الفائدة على القروض الزراعِية & $(\wedge)$ \\
\hline
\end{tabular}

المصدر :جمعت وحسبت من بيانات جدول رقم (Г)

ثانياً: القروض الممنوحة من جهاز تنمية المشروعات للمشروعات الصغيرة بمحافظة البحيرة خلال الفترة (.1. ؟.$(r+11$

تبين بدراسة البيانات الواردة في الجدول رقم (0) أن إجمالي قيمة القروض المقدمة للمشروعات الزراعية

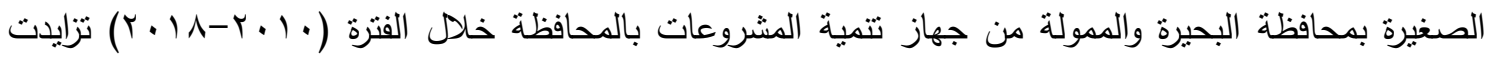

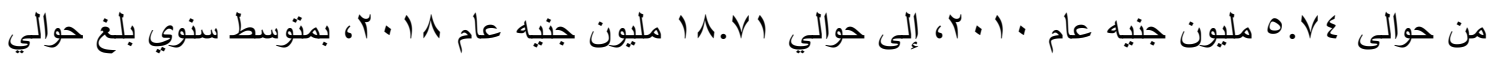

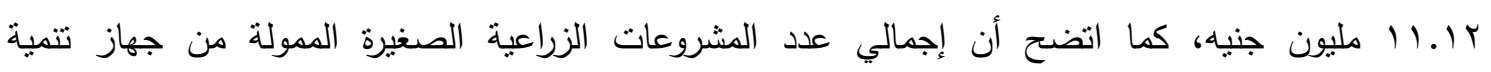

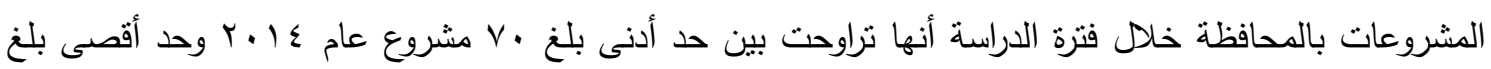

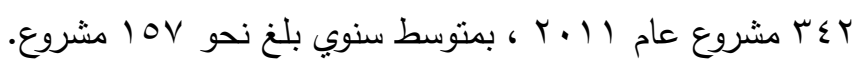

كما تبين أن إجمالي القروض الممنوحة من جهاز تتمية المشروعات للمرأة الريفية بمحافظة البحيرة حيث

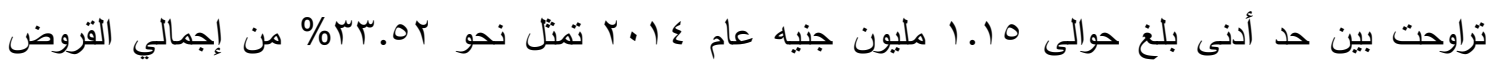

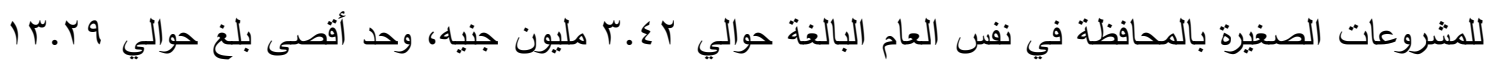

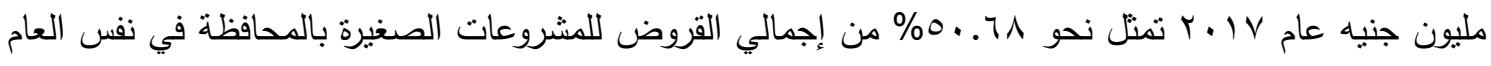

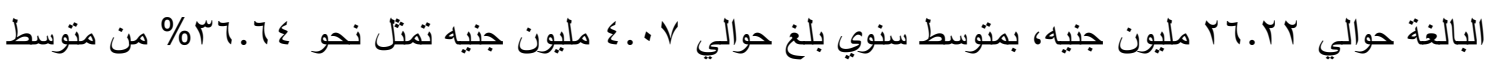

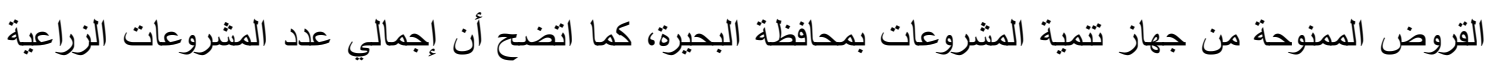

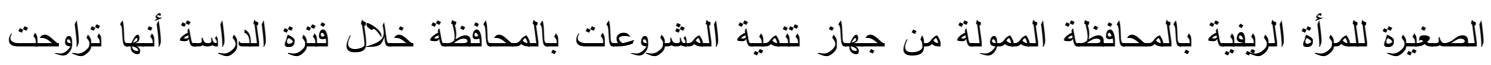

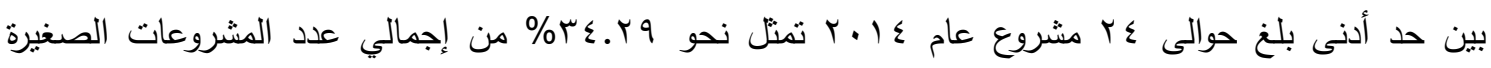

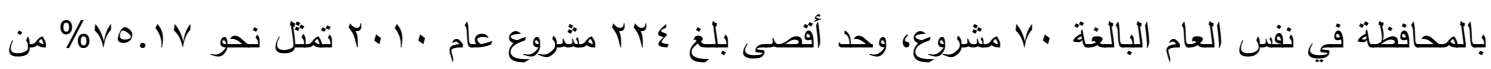
إجمالي عدد المشروعات الصغيرة بالمحافظة من إجمالي عدد المشروعات الصغيرة بالمحافظة في نفس العام البالغة 


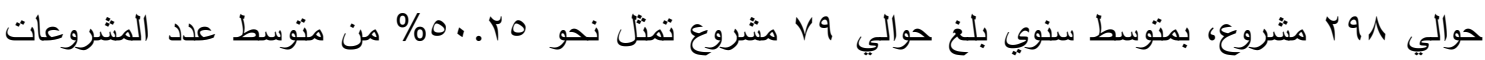
الصغيرة بالمحافظة خلال متوسط فترة الدراسة.

ويتضح أيضاً أن إجمالي القروض الممنوحة من جهاز تتمية المشروعات لشباب محافظة البحيرة نراوحت

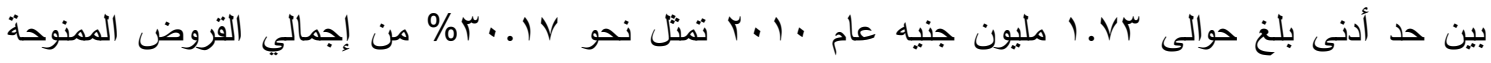

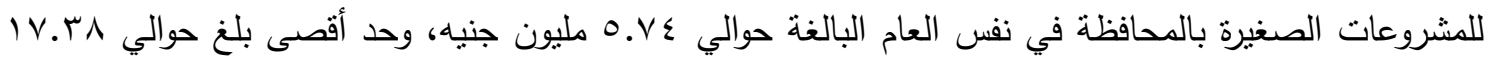

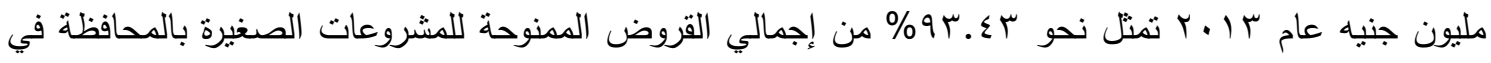

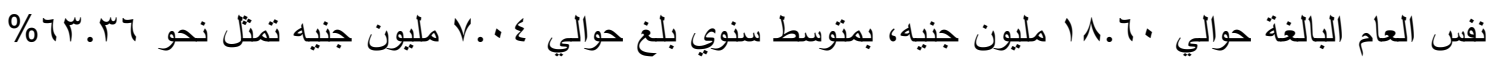
من متوسط القروض الممنوحة من جهاز تتمية المشروعات بالمحافظة، كما اتضح أن إجمالي عدد المشروعات

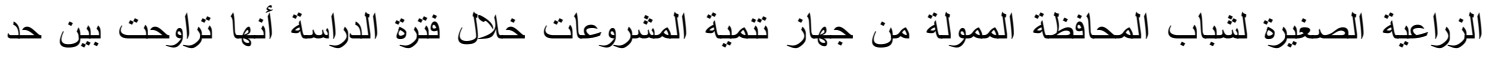

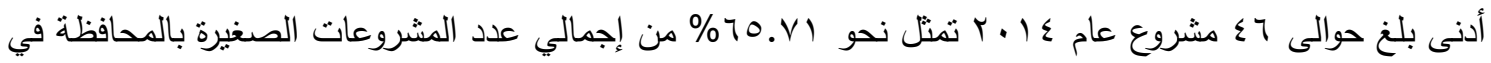

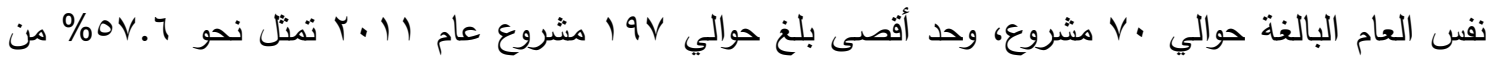
إجمالي عدد المشروعات الصغيرة بالمحافظة في نفس العام البالغة حوالي ب عب مشروع ، بمنوسط سنوي بلغ حوالي

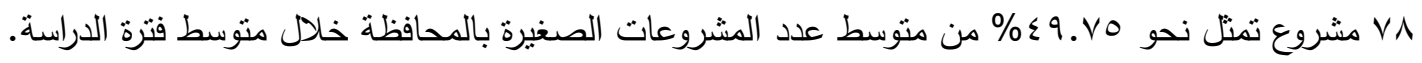

جدول رقم (•): إجمالي قيمة القروض وعدد المشروعات الزراعية الصغيرة للجنسين وأهميتها النسبية والممولة من جهاز

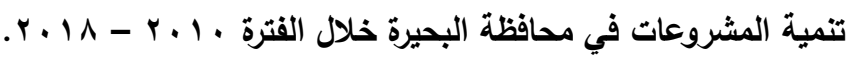

\begin{tabular}{|c|c|c|c|c|c|c|c|c|c|c|}
\hline \multicolumn{4}{|c|}{ شبب الريف } & \multicolumn{4}{|c|}{ المرأة الريفية } & \multirow{2}{*}{\multicolumn{2}{|c|}{ القيمة القى }} & \multirow[b]{2}{*}{ السنة } \\
\hline$\%$ & المثروعات & $\%$ & قليهة القرضن جنيه) & $\%$ & المشروعات & $\%$ & القرضية & & & \\
\hline 24.83 & 74 & 30.17 & 1.73 & 75.17 & 224 & 69.83 & 4.01 & 298 & 5.74 & 2010 \\
\hline 57.60 & 197 & 63.64 & 5.25 & 42.4 & 145 & 36.36 & 3.00 & 342 & 8.25 & 2011 \\
\hline 69.31 & 70 & 75.21 & 3.62 & 30.69 & 31 & 24.79 & 1.19 & 101 & 4.82 & 2012 \\
\hline 63.51 & 47 & 93.43 & 17.38 & 36.49 & 27 & 6.57 & 1.22 & 74 & 18.60 & 2013 \\
\hline 65.71 & 46 & 66.48 & 2.27 & 34.29 & 24 & 33.52 & 1.15 & 70 & 3.42 & 2014 \\
\hline 67.12 & 49 & 64.18 & 2.56 & 32.88 & 24 & 35.82 & 1.43 & 73 & 4.00 & 2015 \\
\hline 72.00 & 72 & 82.54 & 8.50 & 28.00 & 28 & 17.46 & 1.80 & 100 & 10.30 & 2016 \\
\hline 36.95 & 75 & 49.32 & 12.93 & 63.05 & 128 & 50.68 & 13.29 & 203 & 26.22 & 2017 \\
\hline 48.00 & 72 & 48.85 & 9.14 & 52.00 & 78 & 51.15 & 9.57 & 150 & 18.71 & 2018 \\
\hline & 702.0 & & 63.40 & & 709.0 & & 36.66 & 1411 & 100.06 & اجمالي \\
\hline 49.75 & 78.0 & 63.36 & 7.04 & 50.25 & 78.8 & 36.64 & 4.07 & 156.8 & 11.12 & متوسط \\
\hline r.r. r & $v \cdot . r r$ & $7 . . \wedge 7$ & 0.4 & $\leqslant 1.00$ & $0 \leqslant .79$ & $r \cdot . \leqslant 0$ & r.74 & 141.74 & $\Lambda . V r$ & الهندسبي \\
\hline
\end{tabular}


ثالثاً : تقدير الاليل الموسمي للقروض الممنوحة من جهاز تنمية المشروعات للمشروعات الصغيرة بمحافظة

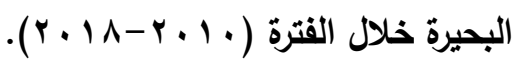

يقصد بالتقلبات الموسمية تلك التغيرات التي تتعرض لها ظاهرة معينة وتتصف بالإنتظام في فترة زمنية متعاقبة يصل مداها إلى إنثى عشر شهراً، وقد يكون شهر معين أو عدة شهور من السنة أو يوم معين من كل شهر

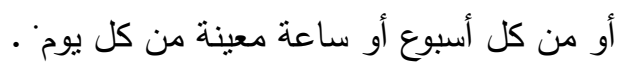

ويعتبر تمويل المشروعات الزراعية الصغيرة من الأمور الهامة التي يعتمد عليها أصحاب نلك المشروعات

وقد تزداد القروض الممنوحة من جهاز تتمية المشروعات للمشروعات الصغيرة بمحافظة البحيرة في أوقات معينة وتتخفض في أوقات أخرى على مدار السنة،الأمر الذي يؤدى إلى أن تلك القروض تتسم بالتقلبات الموسمية خلاد

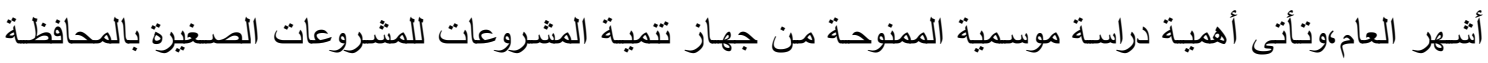

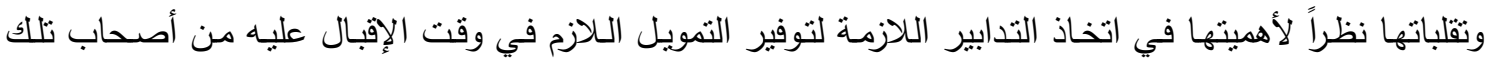
المشروعات.

وبدراسة التقلبات الموسمية لقروض جهاز تتمية المشروعات للمشروعات الصغيرة للمرأة الريفية بمحافظة

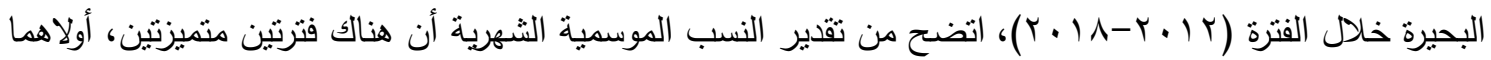
تضم الثهور من فبراير، مارس، مايو، يوليو وديسمبر وتتسم بزيادة القروض المنوحة من جهاز تتمية المشروعات

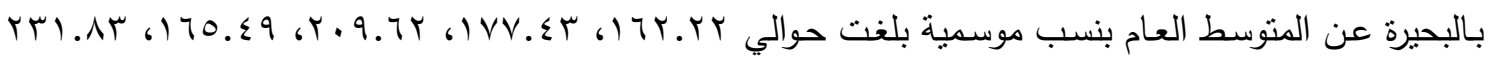
علي الترتيب، أمسا الفترة الثانية فتضم شهور يناير ، إبريل، يونيو، أغسطس ، سبتمبر ، أكتوبر ، نوفمبر ، وتتسم

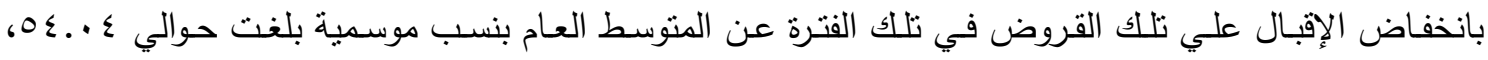
TY.

جدول رقم (†): الدليل الموسـي لقروض جهاز تنميـة المشروعات للمشروعات الصـغيرة للمرأة الريفية بمحافظة

\begin{tabular}{|c|c|c|c|c|c|c|c|c|c|}
\hline \multirow[b]{2}{*}{ الدليل الموسمي } & \multirow[b]{2}{*}{$\begin{array}{r}\text { (\%) } \\
\text { (\% }\end{array}$} & \multirow[b]{2}{*}{$\begin{array}{l}2018 \\
(\%)\end{array}$} & \multicolumn{7}{|c|}{ 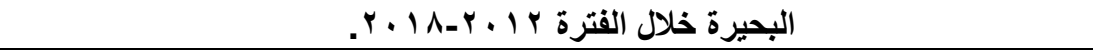 } \\
\hline & & & $\begin{array}{l}2017 \\
(\%)\end{array}$ & $\begin{array}{l}2016 \\
(\%)\end{array}$ & $\begin{array}{l}2015 \\
(\%)\end{array}$ & $\begin{array}{c}2014 \\
(\%)\end{array}$ & $\begin{array}{c}2013 \\
(\%)\end{array}$ & $\begin{array}{c}2012 \\
(\%)\end{array}$ & البيان ان \\
\hline 54.04 & $191 . \times 9$ & 105 & 644 & 205 & 0 & 0 & 220 & 165 & 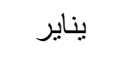 \\
\hline 162.22 & oV纟.r. & 2845 & 617.4 & 90 & 125 & 152 & 155 & 35 & 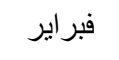 \\
\hline 177.43 & ४r人.. & 1093.4 & 2544.8 & 255 & 105 & 0 & 378.2 & 20 & 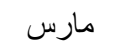 \\
\hline 35.16 & $\mid r \leq . \leq \varepsilon$ & 40 & 0 & 310.9 & 176 & 144.2 & 200 & 0 & ابريل ايل \\
\hline 209.62 & $v \leqslant r \ldots$ & 1927.4 & 2916.6 & 150 & 120 & 0 & 0 & 80 & 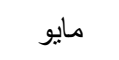 \\
\hline 43.47 & 10r.A4 & 150 & 190 & 125 & 317 & 199 & 0 & 96 & يونيو \\
\hline 165.49 & $0 \wedge \bullet . v \vee$ & 1265.4 & 2583 & 32 & 110 & 0 & 0 & 110 & يوليو \\
\hline 37.78 & $\mid r r . v 1$ & 175 & 140 & 0 & 40 & 375 & 75 & 131 & اغسطس \\
\hline 25.97 & 91.94 & 0 & 140 & 274.5 & 74 & 0 & 0 & 155 & سبتمبر \\
\hline 27.52 & $9 \vee . \leqslant r$ & 0 & 300 & 45 & 59 & 48 & 80 & 150 & اكتوبر \\
\hline 29.49 & I. I.rv & 151.2 & 0 & 50 & 190 & 95 & 194.4 & 50 & نوفمبر \\
\hline 231.83 & Ar..t. & 1819.8 & 3215.4 & 260 & 115 & 132 & 0 & 202 & ديسمبر \\
\hline 100.00 & ror.qv & 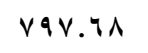 & $11 \cdot 8.7$ & $1 \leq 9 . \vee \wedge$ & $119 . r 0$ & $90 . \leqslant \mu$ & 1.1 .00 & 99.0. & المتوسط \\
\hline
\end{tabular}

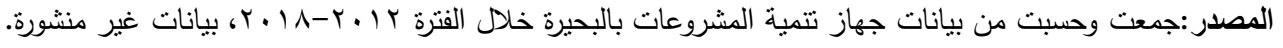




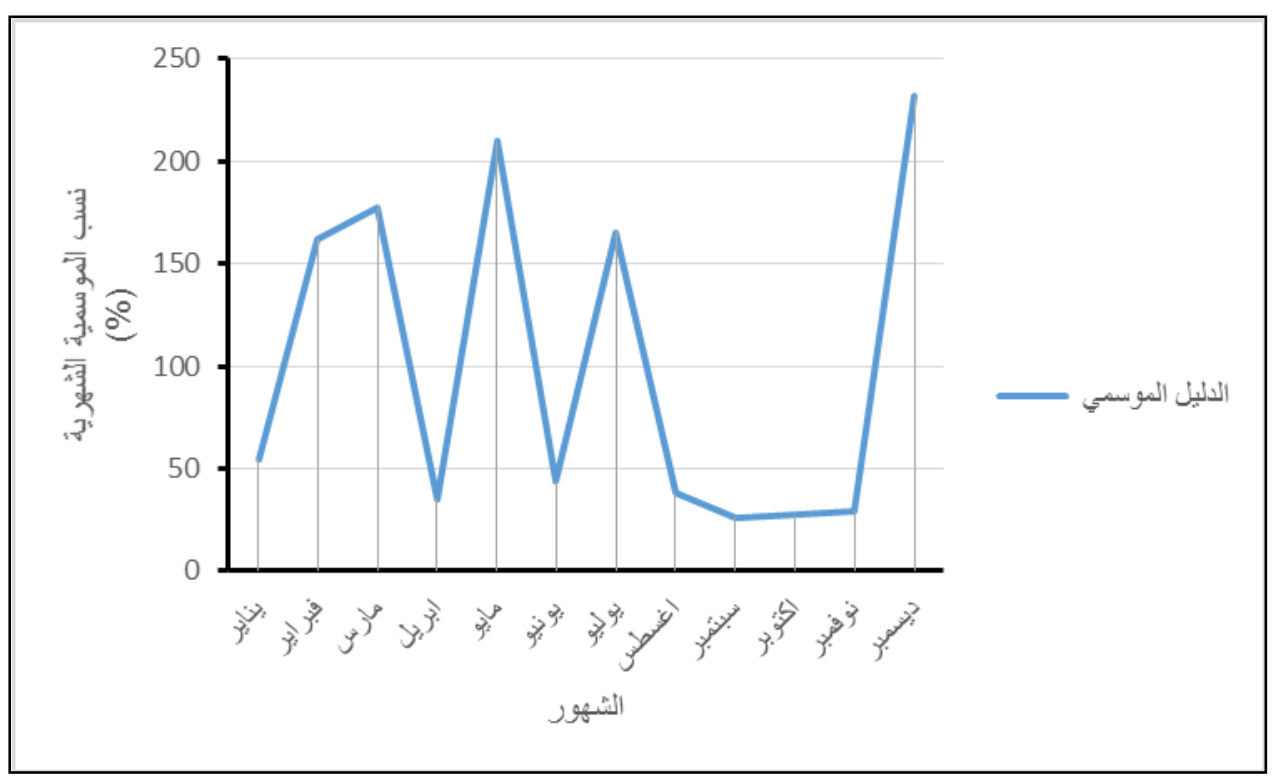

شكل رقم (1): التقلبات الموسمية الشهرية لقروض جهاز تنمية المشروعات للمشروعات الصغيرة للمرأة

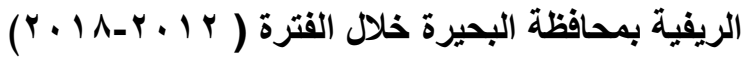

وبدراسة التقلبات الموسمية لقروض جهاز تتمية المشروعات للمشروعات الصغيرة لثباب محافظة البحيرة

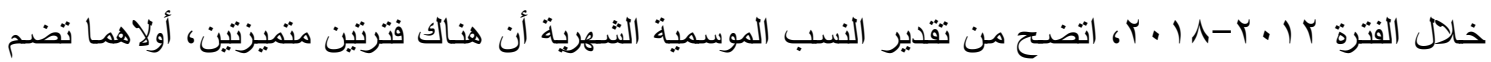
الثهور من فبراير ، مارس، إبريل، مايو ، وديسمبر وتتسم بزيادة القروض الممنوحة من جهاز تتمية الشروعات

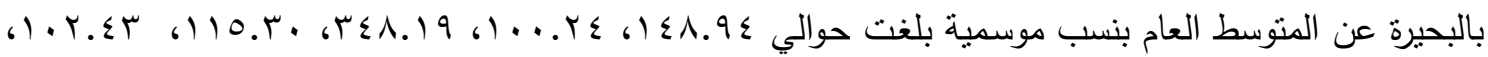

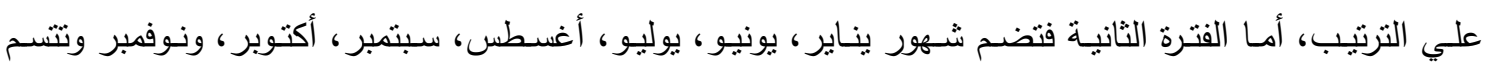
بانخفاض الإقبال علي تللك القروض. جدول رقم (V) وشكل رقم (Y).

جدول رقم (V) : الدليل الموسمي لقروض جهاز تتمية المشروعات للمشرو عات الصغيرة لثباب محافظة البحيرة خلال

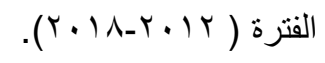

\begin{tabular}{|c|c|c|c|c|c|c|c|c|c|}
\hline $\begin{array}{c}\text { الاليل الموسمي (\%) } \\
\text { (\% }\end{array}$ & $\begin{array}{r}\text { المتوسط } \\
\text { (\%) }\end{array}$ & $\begin{array}{r}2018 \\
(\%)\end{array}$ & $\begin{array}{r}2017 \\
(\%)\end{array}$ & $\begin{array}{r}2016 \\
(\%)\end{array}$ & $\begin{array}{r}2015 \\
(\%)\end{array}$ & $\begin{array}{c}2014 \\
(\%)\end{array}$ & $\begin{array}{c}2013 \\
(\%)\end{array}$ & $\begin{array}{c}2012 \\
(\%)\end{array}$ & البيان \\
\hline 54.12 & rVV.\&. & 371.5 & 1213.3 & 300 & 135 & 25 & 235 & 362 & يناير \\
\hline 148.94 & $1 . r \wedge .7 \varepsilon$ & 2900 & 539.4 & 2674 & 150 & 236.5 & 494 & 276.6 & فبراير \\
\hline 100.29 & 799.49 & 520.6 & 1139 & 1947.6 & 483 & 344 & 461.5 & 0 & مارس \\
\hline 348.19 & r $\leqslant$ Y . I & 843 & 300 & 329 & 120 & 335 & 15070 & 0 & ابريل \\
\hline 115.30 & A. ... & 1216.6 & 2085.4 & 1464.8 & 40 & 494.5 & 30 & 297 & مايو \\
\hline 31.81 & rrI.AT & 692 & 265 & 100 & 132 & 140 & 224 & 0 & يونيو \\
\hline 86.55 & T. T.OV & 544 & 3196 & 80 & 40 & 20 & 150 & 195 & يوليو \\
\hline 52.74 & rqv.vq & 68 & 1036.4 & 152 & 746.1 & 127 & 75 & 370 & اغسطس \\
\hline 38.87 & rVI.. T & 275 & 328.2 & 664.2 & 100 & 200 & 0 & 330 & سبتمبر \\
\hline 65.11 & $\leqslant 0 \leqslant .9$ & 195 & 800 & 717 & 190 & 81.5 & 60 & 1134.9 & اكتوبر \\
\hline 55.64 & 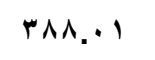 & 794.2 & 182 & 305.9 & 227 & 48 & 579 & 580 & نوفمبر \\
\hline 102.43 & $V \backslash \leq . r T$ & 722.4 & 2830.9 & 429 & 391 & 220 & 0 & 407 & ديسمبر \\
\hline 100.00 & 998.49 & VII.AT & 1109.74 & VIT.Tr & rYq.01 & $1 \wedge 9.19$ & $I \leqslant \leqslant \wedge . Y 1$ & rYq.rA & المتوسط \\
\hline
\end{tabular}

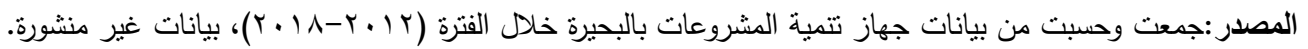




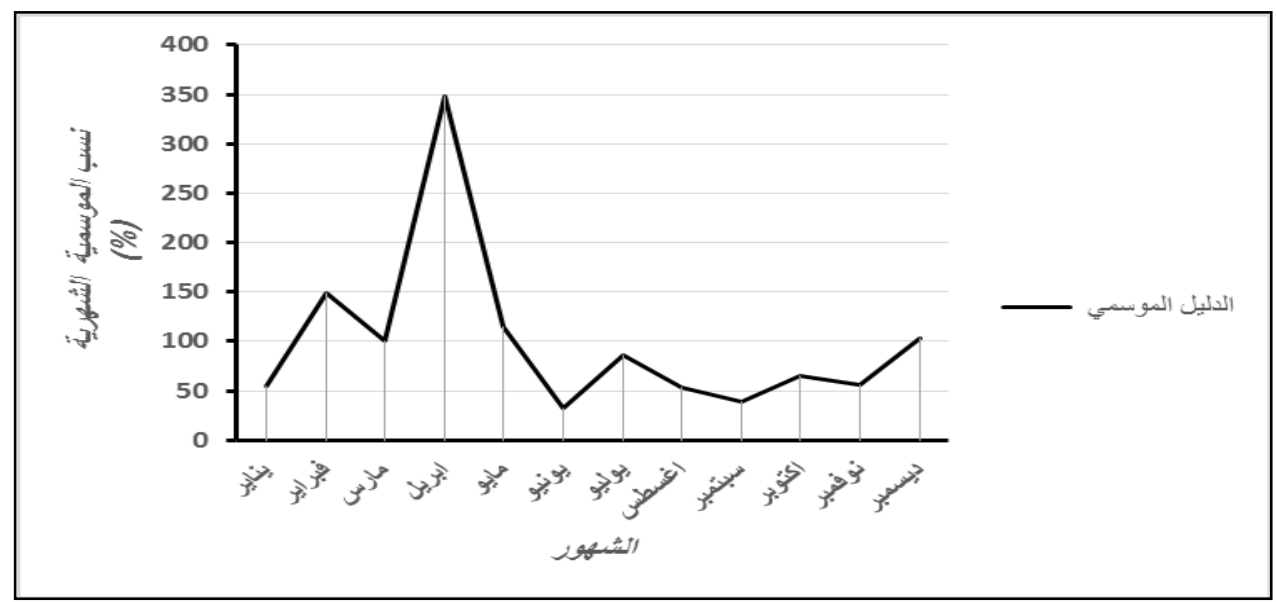

شكل رقم (ץ) : التقلبات الموسمية الثهرية لقروض جهاز تنمية المشروعات للمشروعات الصغيرة لثباب

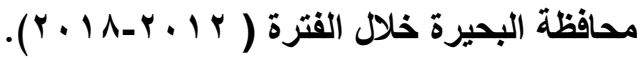

وبدراسة التقلبات الموسمية لإجمالي قروض جهاز تتمية المشروعات للمشروعات الصغيرة بمحافظة

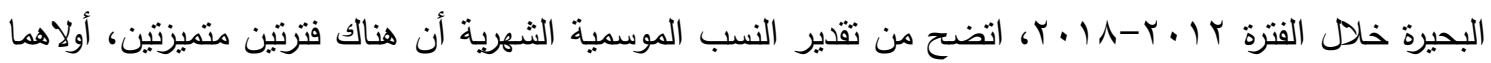
تضم الثهور من فبراير، مارس، إيريل، مايو ، يوليو وديسمبر وتتسم بزيادة القروض الممنوحة من جهاز تتمية

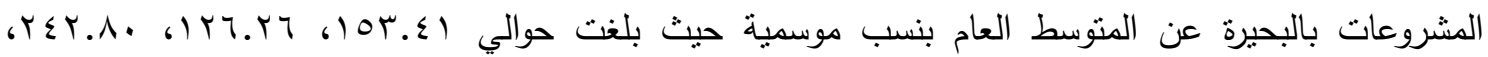

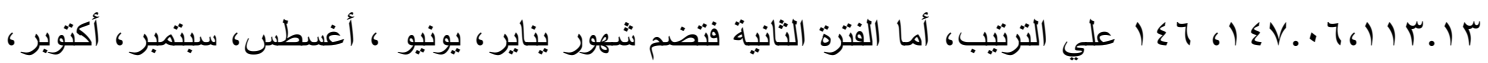
ونوفمبر وتتسم بانخفاض الإقبال علي نلك القروض عن المتوسط العام بنسب موسمية حيث بلغت حوالي 9 ..ـ؛ ه،

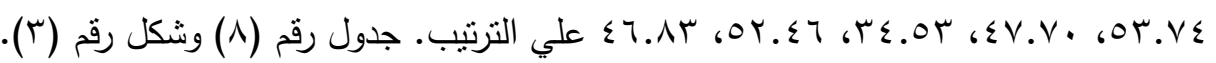
جدول رقم (^) : الدليل الموسمي لقروض جهاز تنميـة المشروعات للمشروعات الصغيرة لثباب محافظة البحيرة خلال

\begin{tabular}{|c|c|c|c|c|c|c|c|c|c|}
\hline & & & & & & $(r \cdot) \Lambda-r$ & الفترة ( r & & \\
\hline الاليل الموسمي & $\begin{array}{c}\text { المتوسط } \\
\text { (\%) }\end{array}$ & $\begin{array}{r}2018 \\
(\%)\end{array}$ & $\begin{array}{r}2017 \\
(\%)\end{array}$ & $\begin{array}{r}2016 \\
(\%)\end{array}$ & $\begin{array}{r}2015 \\
(\%)\end{array}$ & $\begin{array}{r}2014 \\
(\%)\end{array}$ & $\begin{array}{c}2013 \\
(\%)\end{array}$ & $\begin{array}{c}2012 \\
(\%)\end{array}$ & $\begin{array}{l}\text { البيان } \\
\text { (\%) }\end{array}$ \\
\hline 54.09 & 041.79 & 476.5 & 1857.3 & 505 & 135 & 25 & 455 & 527 & يناير \\
\hline 153.41 & ITIY.A & 5745 & 1156.8 & 2764 & 275 & 388.5 & 649 & 311.6 & فبراير \\
\hline 126.26 & ITrV.s & 1614 & 3683.8 & 2202.6 & 588 & 344 & 839.7 & 20 & مارس \\
\hline 242.80 & roor.oq & 883 & 300 & 639.9 & 296 & 479.2 & 15270 & 0 & ابريل \\
\hline 147.06 & $10 \leqslant 4 . .8$ & 3144 & 5002 & 1614.8 & 160 & 494.5 & 30 & 377 & مايو \\
\hline 35.74 & rvo.vi & 842 & 455 & 225 & 449 & 339 & 224 & 96 & يونيو \\
\hline 113.13 & $11 \wedge 9 . r \varepsilon$ & 1809.4 & 5779 & 112 & 150 & 20 & 150 & 305 & يوليو \\
\hline 47.70 & 0.1 .0$. & 243 & 1176.4 & 152 & 786.1 & 502 & 150 & 501 & اغسطس \\
\hline 34.53 & r.4.99 & 275 & 468.2 & 938.7 & 174 & 200 & 0 & 485 & سبتمبر \\
\hline 52.46 & $001 . \leqslant 9$ & 195 & 1100 & 762 & 249 & 129.5 & 140 & 1284.9 & اكتوبر \\
\hline 46.83 & \& १५. १ & 945.4 & 182 & 355.9 & 417 & 143 & 773.4 & 630 & نوفمبر \\
\hline 146.00 & lor 1.94 & 2542.2 & 6046.3 & 689 & 506 & 352 & 0 & 609 & ديسمبر \\
\hline 100.00 & $1.01 . r \mu$ & $1009.0 \leq$ & YrYV.rY & $914 . \& 1$ & $r \leqslant \wedge . \vee ฯ$ & $r \wedge \varepsilon . V T$ & 1004.14 & $\varepsilon Y \wedge . \wedge \wedge$ & المتوسط \\
\hline
\end{tabular}




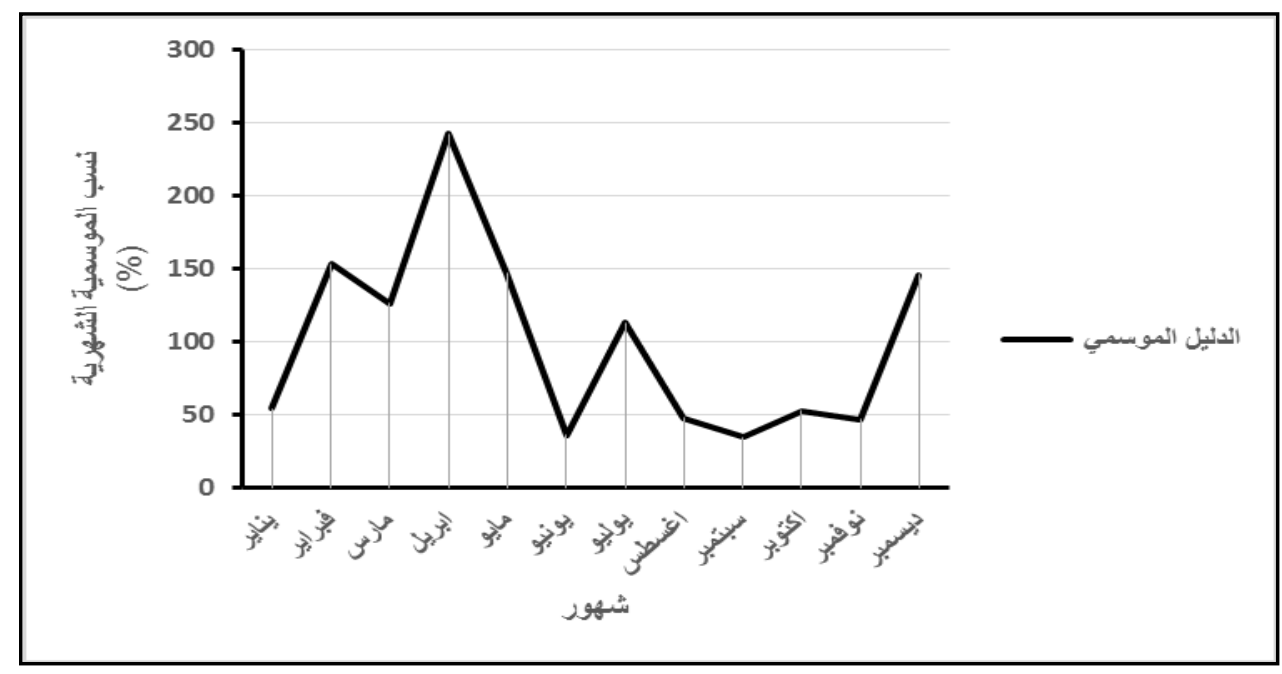

شكل رقم (r) : التقلبات الموسمية الشهرية لقروض جهاز تنمية المشروعات للمشروعات الصغيرة بمحافظة

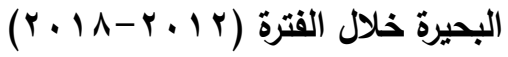

رابعاً : تحليل التباين لمفردات العينة البحثية في محافظة البحيرة ينطوي هذا التحليل للتباين على محاولة التعرف على ما إذا كان المستوى الحالي للقروض الممنوحة من جهاز تتمية المشروعات بالبحيرة للجنسين يسمح بوجود أو عدم وجود ظاهرة اقتصاديات العائد إلى السعة وذللك من عن لئن خلال دراسـة اقتصـاديات العائد إلى السعة في مزارع تتباين في سعاتها المزرعية والتعرف على مدى وجود فروق

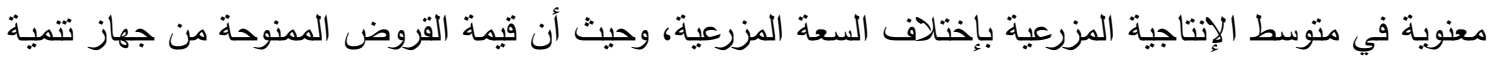
المشروعات للجنسين بمحافظة البحيرة تعكس حجم المشروعات المقامة وسعاتها الإنتاجية بالمحافظة.

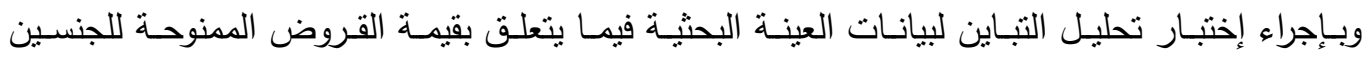
بالمحافظة والذي يتضح منه عدم وجود فروق معنوية بين متوسطات قيم تللك القروض لإقامة المشروعات الصغيرة

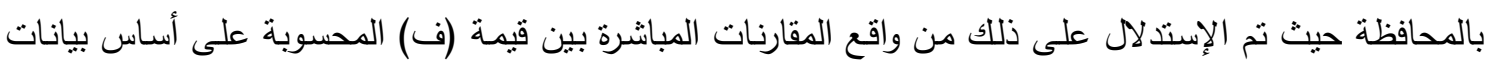
العينة البحثية وبين قيمتها الجدولية عند مستويات المعنوية ا...، هـ....

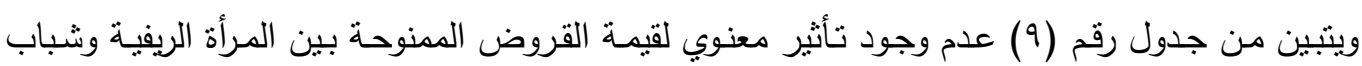

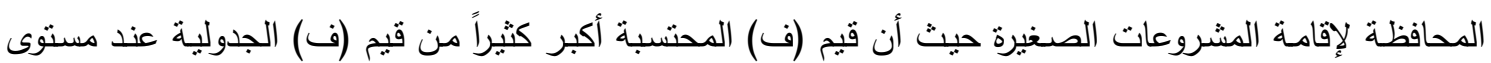

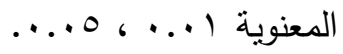

جدول رقم (9): تحليل التباين لإختبار مغنوية الفروق بين قيم القروض الممنوحة من جهاز تنمية المشروعات بمحافظة

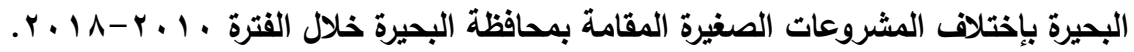

\begin{tabular}{|c|c|c|c|c|c|}
\hline $\begin{array}{l}\text { Ft ( } \\
0.01)\end{array}$ & المحتبة فة & الإنحر|فات مربع M.S & $\begin{array}{l}\text { درجات الحرية } \\
\text { D.F. }\end{array}$ & الإنحرافات مجموع مربع & مصدر التباين \\
\hline \multirow[t]{3}{*}{1.04} & 1.749 & 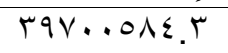 & 1 & $r q \vee . .0 \wedge \varepsilon . r$ & التباين بين السعات \\
\hline & & $r \leq r \mid \wedge T \leq 0.9$ & 17 & $\mu \wedge \vee \leqslant q \wedge r r \varepsilon$. & التباين داخل السعات \\
\hline & & & IV & $\varepsilon r \vee \backslash ৭ \wedge q \backslash \wedge . r$ & الكلي \\
\hline
\end{tabular}

المصدر: جمعت وحسبت من: بيانات جهاز تتمية المشروعات بمحافظة البحيرة بيانات غير منشورة. 
خامساً : تقييم مشروع تسمين عجول بطاقة ـ رأس بمحافظة البحيرة.

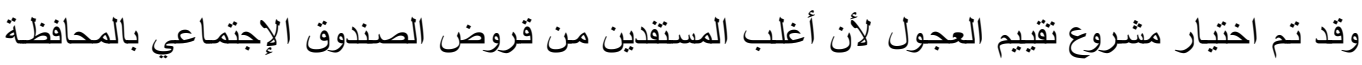

يقومون بهذا النشاط. الأهداف المرتقبة من مشروعات تسمين العجول: (1) زيادة الإنتاج من اللحوم الحمراء وذللك وإمكانية سد جزء من

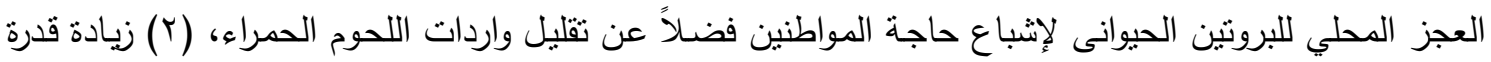
الاقتصاد القومي على تتغيل عوامل الإنتاج وتوفير فرص العمل، ورأس المال والأرض والإدارة بالثنكل الذبي يساهم في حل مشكلة البطالة، (؟) تعظيم ربح المنتج لأنه الهدف الذي يسعى لتحقيقه كعائد على رأس المال المستتمر

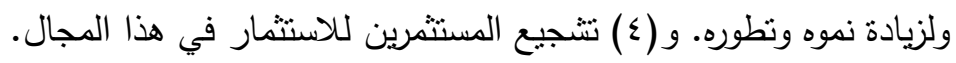
نظام التربية المتبع: هو النظام العنابر المغلقة، حيث تقف الحيوانـات في صفين مثقابلة الذيل، ويوجد نظامان للحظائر ذات الصفين، فإما أن تكون متقابلة الرؤس أو منقابلة الذيل، ويتميز نظام تقابل الرعوس بسهولة تقديم

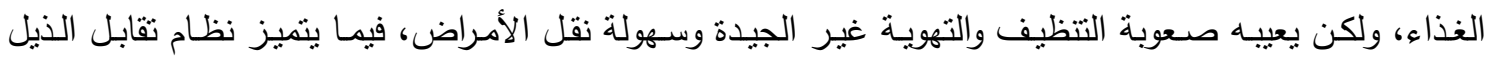

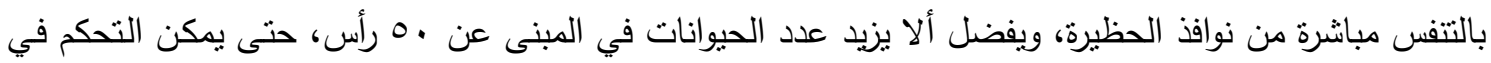
التهوية والرعاية.

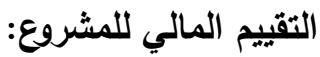
الطاقة الإنتاجية للمشروع: عدد الرؤوس = •0 رأس، عدد الدورات في العام = r، بحيث تبدأ دورة التسمين بعجول متوسط وزنها حوالي . . ب كجم. متوسط إنتاج المشروع السنوي = . . 1 عجل/سنة بمتوسط وزن . . . ع كجم/عجل أي حوالي . ـ طن لحم قائم/سنه.

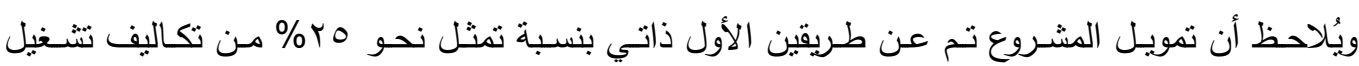

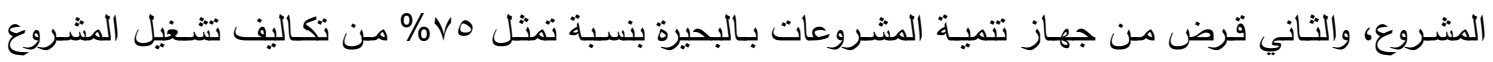
المشروع، لمدة خمس سنوات يسدد على أربعة أقساط، حيث أن السنة الأولى معفاه من دفع أقساط.

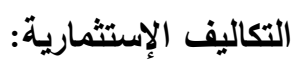

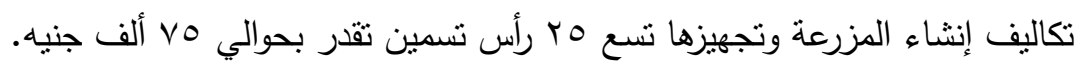

التكاليف التشغيلية: 1- تكاليف شراء عجول التسمين:

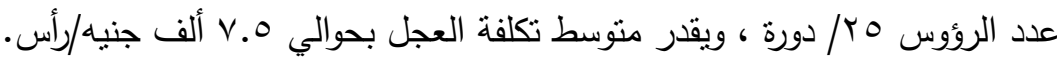

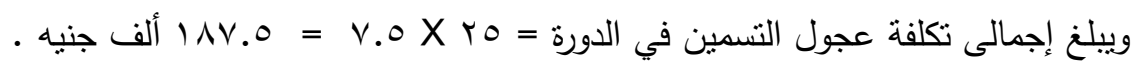

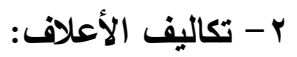

اتضـح من خلال سؤال المنتجين أنهم يقومون باستخدام نوعين من العلف وهما العلف المركز ويستخدم

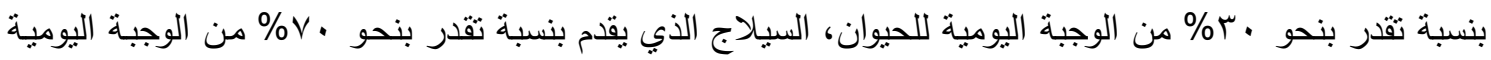

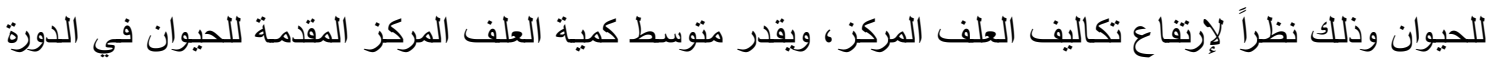

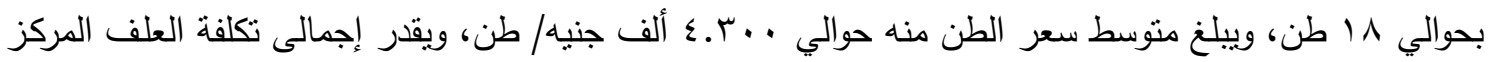
في الدورة بحوالي . . ع. PV. ألف جنيه. كما يبلغ منوسط كمية السيلاج المقدمة للحيوان في الدورة بحوالي عه طن، ويبلغ منوسط سعر الطن منهـ

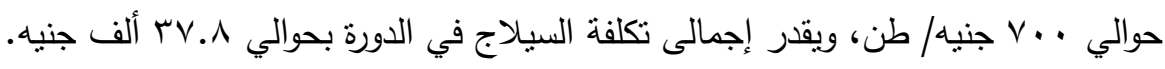


كما يبلغ متوسط كمية قش الأرز المكبوس في الدورة بحوالي ه. 1 طن، ويقدر إجمالى تكلفة قش الأرز في الدورة بحوالي م ب ألف جنيه.

r-تكاليف العمالة اللازمة للمزرعة: يحتاج المشروع لعامل واحد، بلتغ متوسط تكاليف العمالة السنوي حوالى بـ ألف جنيه، بواقع r آلاف جنيه شهرياً. ع- تكاليف الرعايـة البيطريـة: بلـغ متوسط تكاليف الأدويـة والتحصينات حوالي 10 ألف جنيه/|دوره، بلغ متوسط الإشراف البيطري حوالى V.r ألف جنيه/دورة.

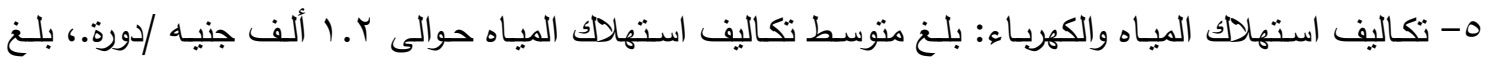
متوسط تكاليف استهلاك الكهرباء حوالى . .7 جنيه/دورة. جدول (· ( ) إيرادات المشروع: (1)

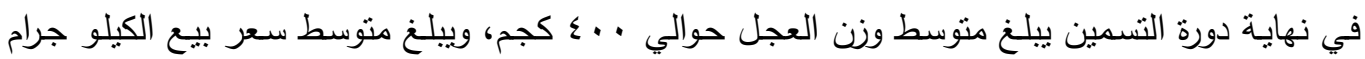

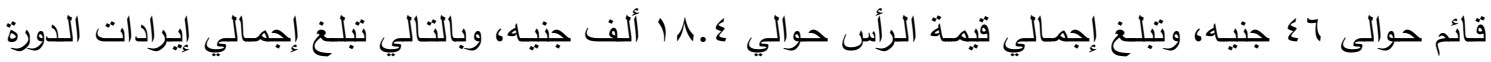

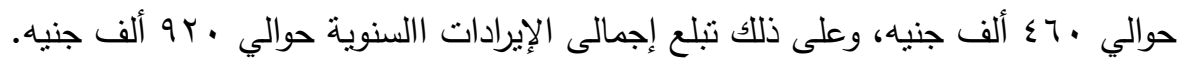
نتائج التحليل المالى للمشروع: فروض التحليل : (1) نم إفتراض سعر الخصم • ( ) (منوسط سعر الفائدة على الودائع فى البنوك)، وذلك لإجراء

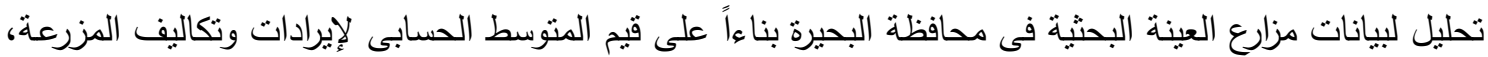
(Y) نم إفتراض العمر الإنتاجى للمشروع • 1 سنوات.

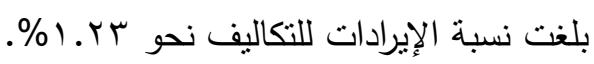

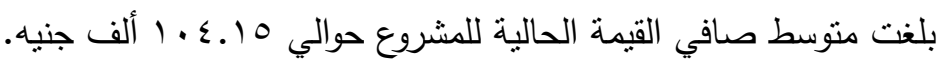

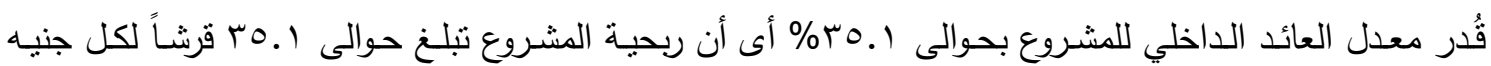

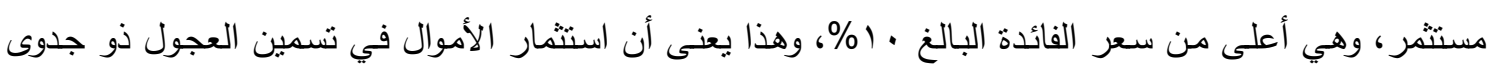

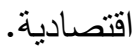

\section{تحليل الحساسية للمشروع في حالة زيادة التكاليف بنسبة 1\%:}

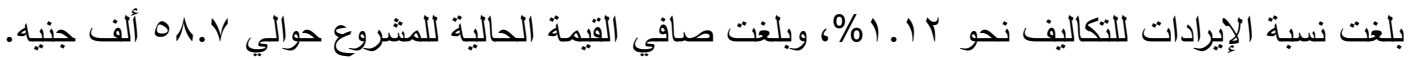

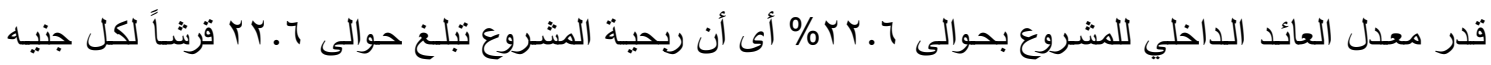

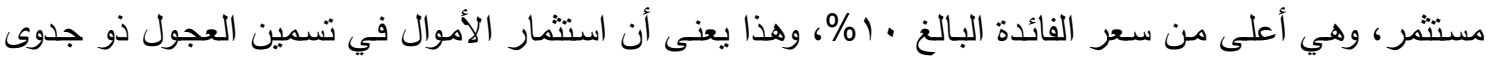

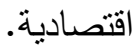

تحليل الحساسية للمشروع في حالة انخفاض الإيرادات بنسبة . 1\% \%

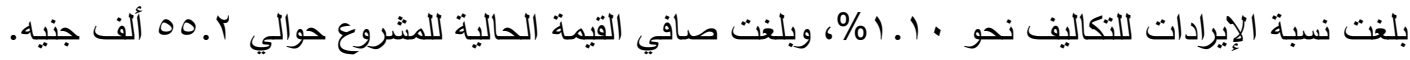

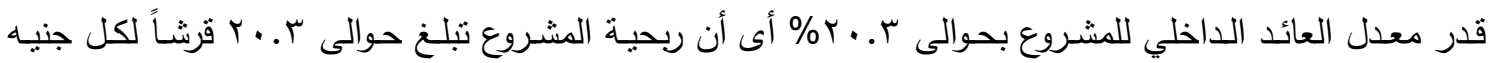

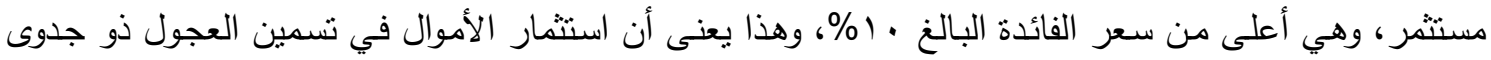


جدول ( • () : متوسط قيمة تكاليف إنشاء مزرعة تسمين عجول وإيراداتها بالعينة البحثية بمحافظة البحيرة عام 9 ـ. ب.

\begin{tabular}{|c|c|}
\hline & التكاليف الاستثمارية \\
\hline \multirow[t]{3}{*}{75000} & تكلفة إنشاء العنبر بالجنيه \\
\hline & تكاليف التشغيل \\
\hline & تكلفة العجول \\
\hline 25 & العدد العجول في الدورة بالر أس \\
\hline 7500 & متوسط ثمن الرأس بالجنيه \\
\hline 187500 & اجمالي ثمن العجول في الدورة بالجنيه \\
\hline 375000 & اجمالي ثمن العجول في العام \\
\hline 1 & عدد العمالة \\
\hline 18000 & اجمالي اجور العمال في الدورة بالجنيه \\
\hline \multirow[t]{2}{*}{216000} & اجمالي اجور العمال السنوية بالجنيه \\
\hline & العليقة الجافة \\
\hline 18 & كمية العلف في دورة التسمين بالطن \\
\hline 4300 & سعر الطن بالجنيه \\
\hline \multirow[t]{2}{*}{77400} & قيمة العلف في الدورة بالجنيه \\
\hline & العلف المالئ السيلاج \\
\hline 54 & كمية السيلاج في دورة التسمين بالطن \\
\hline 700 & سعر الطن من السيلاج بالجنيه \\
\hline 37800 & قيمة السيلاج في الدورة بالجنيه \\
\hline 12500 & كمية القش المستخدم بالجنيه في العام \\
\hline \multirow[t]{2}{*}{25000} & قيمة القش المستخدم بالجنيه في العام \\
\hline & الأدوية \\
\hline 600 & تحصينات الدورة بالجنيه / عجل \\
\hline 15000 & اجمالي التحصينات بالجنيه / دورة \\
\hline 7200 & اشراف بيطري بالجنيه \\
\hline 1200 & قيمة المياه في الدورة بالجنيه \\
\hline 2400 & قيمة المياه في السنة بالجنيه \\
\hline 600 & قيمة الكهرباء في الدورة بالجنيه \\
\hline 1200 & قيمة الكهرباء في السنة بالجنيه \\
\hline 369700 & إجمالي تكاليف التشغيل في الدورة بالجنيه \\
\hline 739400 & اجمالي تكاليف التشغيل في العام بالجنيه \\
\hline \multirow[t]{2}{*}{814400} & اجمالي التكاليف بالجنيه \\
\hline & المبيعات \\
\hline 400 & متوسط وزن الرأس كجم \\
\hline 46 & سعر الكيلوقائم بالجنيه \\
\hline 460000 & اجمالي مبيعات الدورة بالجنيه \\
\hline 920000 & اجمالي مبيعات العام بالجنيه \\
\hline 180600 & صافي الربح في دورة التسمين بالجنيه \\
\hline 361200 & صافي الربح في العام بالجنيه \\
\hline 30100 & صافي الربح في الثهر بالجنيه \\
\hline
\end{tabular}


بلغ إجمالي تكاليف التشغيل السنوية للمشروع حوالي ع. ع و ألف جنيه، وعلى ذللك فإن قيمة القرض

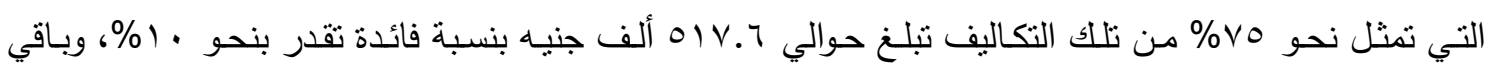
تكاليف المشروع تتم ذاتياً.

يتم سداد القرض على خمس سنوات السنة الأولى معفاه من دفع القسط ويتم دفع الفائدة على أصل القرض فقط،

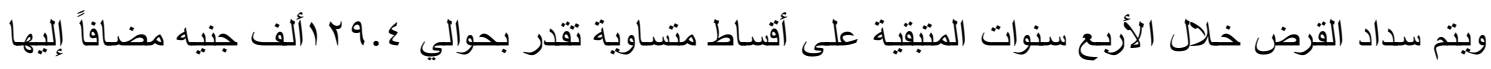

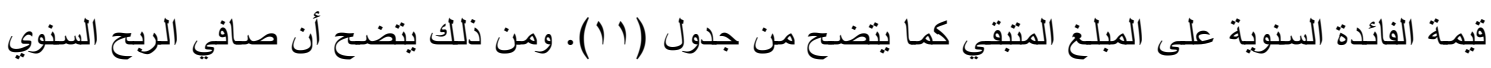

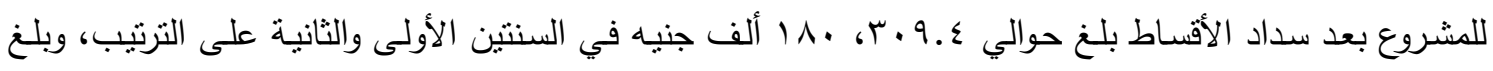

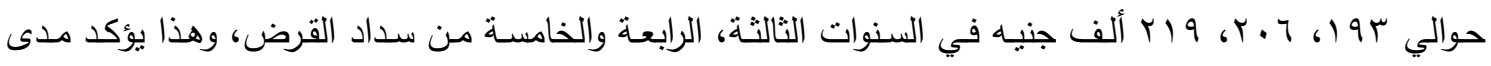

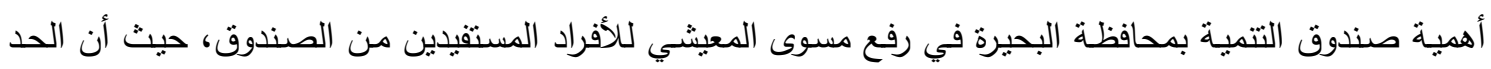

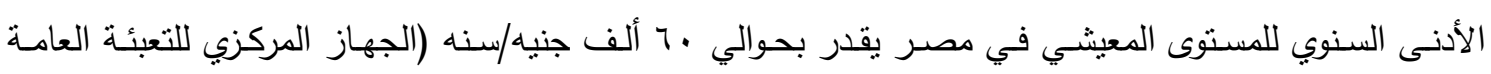

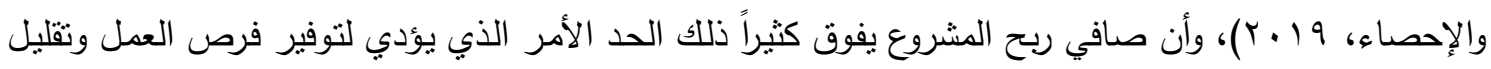
البطالة من ناحية، ورفع المستوى المعيشي ومحاربة الفقر لهؤلاء الأفراد.

جدول (11): قيمة القرض والفائدة السنوية والقسط السنوي بالجنيه الذي يتحمله المقترض وصافي الريح بعد سداد الأقساط السنوية.

\begin{tabular}{|c|c|c|c|c|c|}
\hline صدافي الربّح بعد الأقساط & مجموع القسط + الفوائد & القسط السنوي & الفائدة السنوية & رصيد القرض & السنة \\
\hline 0 & 0 & & & 517580 & 0 \\
\hline 309442 & 51758 & & 51758 & 517580 & 1 \\
\hline 180047 & 181153 & 129395 & 51758 & 388185 & 2 \\
\hline 192987 & 168214 & 129395 & 38819 & 258790 & 3 \\
\hline 205926 & 155274 & 129395 & 25879 & 129395 & 4 \\
\hline \multirow[t]{2}{*}{218866} & 142335 & 129395 & 12940 & 0 & 5 \\
\hline & & 517580 & 181154 & & إجمالي \\
\hline
\end{tabular}

المصدر: جمعت وحسبت من بيانات استبيان بمحافظة البحيرة عام 9 أ. 


\section{المراجع}

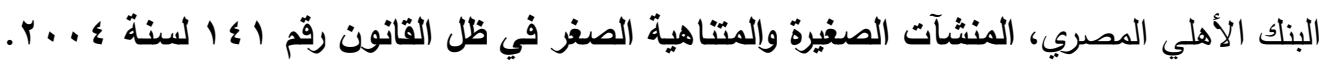

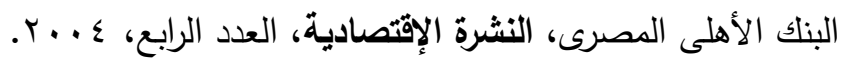
الصندوق الاجتماعي لتنمية الشركات. الجهاز المركزى للتعبئة العامة والإحصاء، دراسة المؤسسات غير المصرفية الحكومية ودورها فى تمويل

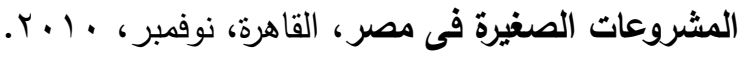
مديرية الزراعة، قسم الإنتاج الحيوانى، إحصاءات الثروة الداجنة، بيانات غير منشورة. وزارة التتمية الاقتصادية، خطة التتمية الاقتصادية والإجتماعية، أعداد متفرقة. (الموقع الإكتروني للهيئة العامة للإستعلامات (https://sis.gov.eg).

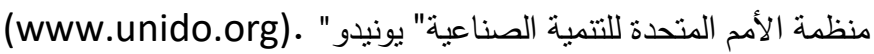
البنك الدولي الشرروعات.(documents1.worldbank.org) جهاز تنمية المشروعات بمحافظة البحيرة ، بيانات غير منشورة. 


\section{SUMMARY}

\section{Small Agricultural Projects and their role in Reducing Unemployment and its Impact on Sustainable Development in Egypt}

\section{Sherien Mohamed Efat Elfar}

(First Researcher)
Doaa Ibrahim A. hamid Hashem

(Researcher)

Agricultural Economic Research Institute

The research aims to identify the role of small projects in agricultural development by studying the current status of each: 1 - the total agricultural labor force and its relative importance during the period (2005-2017). 2 - National investment and public and private agricultural investments and loans granted to small projects in Beheira Governorate during the period (2010 -2018). 3- Estimating the seasonal guide for loans granted to small projects in Beheira Governorate during the period (2010-2018).

The most important results showed that total labor force increased from about 22 million individuals in 2005 to about 29 million individuals in 2017 amount \% rr.9, and total agricultural labor force increased from 5.2 million individuals in In 2005 to 7.1 million individuals learned in 2017, with an average 6.2 million individuals. Total value of loans of small agricultural projects in Beheira Governorate increased from 5.74 million pounds in 2010 to 18.71 million pounds in 2018. total number of funded small projects ranged between the minimum about 70 projects in 2014 and a maximum of 342 projects in 2011 with an annual average about 157 projects ,The seasonal fluctuations of the loans of the Small Enterprise Development Agency showed that there are two distinct periods for loans granted to rural women, which are February, March, May, July, December and are characterized by an increase in loans granted, while decreasing in the second period, which includes the January, April, June, August, September, While the loans granted to the youth of the governorate increased in the months of February, March, April, May and December, while the demand for these loans decreased in January, June, July, August and September, and for the total loans of the Enterprise Development Authority in the governorate Al-Buhaira during the period (2012-2018). The demand for these loans increased in February, March, April, May, July,December, while it decreased in January, June, August, September, October and November. The research showed that there are no significant differences between the averages of the value of these loans provided to rural women and youth in the governorate by the variance analysis of the sample data. 